\title{
El holobionte/hologenoma como nivel de selección: una aproximación a la evolución de los consorcios de múltiples especies
}

\author{
(The holobiont/hologenome as a level of selection: \\ An approach to the evolution of multispecies systems)
}

\author{
Javier SUÁREZ* \\ Jagiellonian University (Poland)
}

\begin{abstract}
RESUMEN: El debate de las unidades o niveles de selección concierne la pregunta acerca del tipo de sistemas biológicos que son lo suficientemente estables como para que parte de su evolución sea resultado del proceso de selección natural actuando a su nivel. Tradicionalmente, el debate ha concernido al menos dos preguntas diferentes, aunque relacionadas: la pregunta por el nivel en el cual se da la interacción con el ambiente (qué entidad actúa como interactor), y la pregunta por el nivel en que ocurre la reproducción (qué entidad actúa como replicador o reproductor). En los últimos años, biólogos y filósofos han discutido un nuevo aspecto de este debate, a saber: la posibilidad de que ciertos consorcios de múltiples especies formados por un hospedero y su microbioma (holobiontes/hologenomas) puedan actuar como una unidad de selección. Dicha tesis, no obstante, no ha estado exenta de crítica, ya que es dudoso que tales consorcios puedan reunir las condiciones requeridas para alcanzar el grado de estabilidad suficiente que permitiría que actuasen como unidades de selección. El presente artículo tiene como objetivo examinar sistemáticamente tales críticas y defender la tesis de que el holobionte/hologenoma puede actuar como un nivel de selección genuino tanto en la forma de interactor como en la forma de reproductor. Para ello, se argumentará que el microbioma debe caracterizarse en términos funcionales, en vez de en términos taxonómicos.
\end{abstract}

PALABRAS CLAVE: niveles/unidades de selección; selección natural; interactor; reproductor; hologenoma; microbiota; teoría de la evolución.

\begin{abstract}
The units or levels of selection debate concerns the question of what kind of biological systems are stable enough that part of their evolution is a result of the process of natural selection acting at their level. Traditionally, the debate has concerned at least two different, though related, questions: the question of the level at which interaction with the environment occurs (which entity acts as an interactor), and the question of the level at which reproduction occurs (which entity acts as a replicator or reproducer). In recent years, biologists and philosophers have discussed a new aspect of this debate, namely the possibility that certain multi-species consortia formed by a host and its microbiome (holobionts/ hologenomes) may act as a unit of selection. This thesis, however, has not been without criticism, as it is doubtful that such consortia could meet the conditions required to achieve the degree of stability that would allow them to experience natural selection. The purpose of this paper is to systematically examine such criticisms and to defend the thesis that the holobiont/hologenome can act as a genuine level of selection both in the form of an interactor and in the form of a reproducer. To do so, it will be argued that the microbiome should be characterized in functional rather than taxonomic terms.
\end{abstract}

KEYWORDS: units/levels of selection; natural selection; interactor; reproducer; hologenome; microbiota; evolutionary theory.

* Correspondencia a/Correspondence to: Javier Suárez. Department of Philosophy of the Natural Sciences, Institute of Philosophy, JagieIlonian University. Grodka 52, Room 42, 33-332, Krakow (Poland) - javier.suarez@uj.edu.pl - https://orcid.org/0000-0001-5851-2277

Cómo citar/How to cite: Suárez, Javier. (2021). «El holobionte/hologenoma como nivel de selección: una aproximación a la evolución de los consorcios de múltiples especies»; Theoria. An International Journal for Theory, History and Foundations of Science, 36(1), 81-112. (https://doi.org/10.1387/theoria.21611).

Recibido/Received: 01 abril, 2020; Versión final/Final version: 11 agosto, 2020.

ISSN 0495-4548 - elSSN 2171-679X / (C) 2021 UPV/EHU 
La selección natural es el mecanismo evolutivo, originalmente descrito por Darwin, que produce que los organismos biológicos se adapten a su ambiente. El mecanismo funciona en virtud del hecho de que aquellos rasgos fenotípicos que aumentan la aptitud o eficacia biológica de sus portadores en un determinado ambiente, incrementarán su presencia en la población hasta alcanzar una situación de equilibrio óptimo, toda vez que los rasgos en cuestión sean heredables (Lewontin, 1970; Lloyd, 1994; Ginnobili, 2010: 49; Gildenhuys, 2019). La selección natural es, por tanto, un proceso que resulta de la conexión sistemática que existe entre ciertos rasgos fenotípicos y la eficacia diferencial mayor que dichos rasgos confieren a sus portadores en la población. En virtud de tal conexión, esos rasgos se vuelven predominantes y, en consecuencia, se alcanza un equilibrio a nivel población que hace que tales rasgos se fijen, predominen, o alcancen un cierto nivel de estabilidad. ${ }^{1}$

Formulada de este modo, la teoría de la selección natural da lugar a una serie de preguntas de carácter tanto biológico como filosófico: cómo determinar los límites de la población, cómo entender el concepto de eficacia o aptitud biológica, en qué casos cabe hablar de heredabilidad, etc. Una de tales preguntas es la relativa a cómo deben caracterizarse los portadores de los rasgos fenotípicos que experimentan la selección natural. ¿Son los propios genes? ¿Los gametos? ¿Los organismos pluricelulares (animales, plantas, etc.)? ¿Las colonias en el caso de organismos que forman castas y tienen especificidad reproductiva (ciertas hormigas, abejas, etc.)? Responder a una dimensión específica de dicha pregunta, habitualmente presentada bajo la rúbrica de «pregunta sobre las unidades o niveles de selección» (Okasha, 2006; Godfrey-Smith, 2009; Diéguez, 2012; Lloyd, 2017a; Ginnobili, 2018), ${ }^{2}$ constituirá el objetivo de este trabajo. En concreto, este trabajo se preguntará acerca de la posibilidad de si algunos consorcios de organismos de múltiples especies (multispecies systems/consortia) pueden considerarse portadores de rasgos susceptibles de evolucionar por selección natural. Los consorcios en que centraré la cuestión serán los holobiontes, sistemas formados por un hospedero (animal o planta) más su microbioma simbiótico (Margulis, 1990, 1991; Rohwer et al., 2002).

Recientemente, un grupo de biólogos y filósofos ha argumentado, bajo el marco del llamado concepto de evolución hologenómica, que tales consorcios pueden experimentar selección natural y, por tanto, evolucionar de acuerdo con las dinámicas evolutivas originalmente descritas por Darwin (Zilber-Rosenberg \& Rosenberg, 2008; Dupré \& O’Malley, 2009; Dupré, 2012; Rosenberg \& Zilber-Rosenberg, 2013, 2018; Gilbert et al., 2012; Díaz, 2015; Cerqueda-García \& Falcón, 2016; Theis et al., 2016; Lloyd, 2017b). No obstante, tal visión ha sido criticada severamente debido a que es dudoso que la totalidad de los organismos que constituyen un holobionte sean lo suficientemente estables tanto intra- como trans-generacionalmente como para constituir una totalidad lo suficientemente coherente que pueda clasificarse como unidad de selección (Booth, 2014; Moran \& Sloan,

1 Hay diferentes condiciones y diferentes tipos de equilibrio que pueden resultar de un proceso de selección natural, no solamente la fijación del rasgo fenotípico entre todos los portadores del rasgo en la población. Muchos de tales equilibrios dependen de condiciones específicas sobre los patrones de expresión y/o heredabilidad del rasgo. Examinarlo está fuera del alcance de este trabajo. Se pueden encontrar revisiones interesantes en Sober (1993), Okasha (2006), Godfrey-Smith (2009), Frank (2011), o Diéguez (2012).

2 Utilizaré los términos «nivel de selección»y «unidad de selección» de manera intercambiable, pues es la convención general en biología y filosofía de la biología. Para otro criterio véase Brandon (1988). 
2015; Douglas \& Werren, 2016; Skillings, 2016; Hurst, 2017; Stencel \& Proszwska, 2017; Bourrat \& Griffiths, 2018). Esto ha generado un debate de naturaleza tanto filosófica como biológica, dando lugar a cuestiones filosóficas de índole muy diversa. Esto incluye cuestiones sobre si los holobiontes son realmente unidades de selección y, de serlo, si son tanto interactores como reproductores. Así como si es posible caracterizar rasgos a nivel del holobionte/hologenoma, y/o predicar de algunos de tales rasgos que constituyen adaptaciones a nivel del holobionte/hologenoma (más bien que a nivel de los organismos que los componen).

En esta línea, en este trabajo argumentaré la tesis restringida de que los holobiontes son unidades de selección tanto en su forma de interactor como en su forma de reproductor, si el microbioma se define de forma funcional — de acuerdo con la idea de «estabilidad de rasgos» (stability of traits) defendida en Suárez \& Triviño (2019) y Suárez (2020)—, en vez de en forma taxonómica.

La estructura del artículo será la siguiente: en la primera sección explicaré el problema de las unidades de selección, poniendo el énfasis en que la pregunta por las unidades de selección puede hacer tanto referencia a la pregunta por la unidad de interacción como a la pregunta por la unidad de reproducción. En la sección 2, explicaré el concepto hologenómico de evolución. En la sección 3, mostraré la debilidad de los argumentos que niegan que los holobiontes sean interactores, y argumentaré que la tesis de que son unidades de interacción en ciertos sistemas biológicos es perfectamente compatible con lo evidencia empírica existente, si esta se interpreta desde la perspectiva de la estabilidad de rasgos. En la sección 4 haré lo mismo, pero desde la perspectiva del reproductor. Finalmente, presentaré las conclusiones del trabajo.

\section{El debate de las unidades de selección}

Aunque el problema de las unidades de selección se encuentra esbozado en los trabajos del propio Darwin -especialmente en El origen del hombre y la selección en relación al sexo (1874), aunque ya aparecen algunas menciones en El origen de las especies (1859), ver Ginnobili (2018, pp. 166-178) -, el origen del debate acerca de qué entidades satisfacen las condiciones para ser una unidad de selección se atribuye habitualmente a Lewontin (1970), en su trabajo «Las unidades de selección», y su formalización matemática más elaborada a Price (1970, 1972) (ver Okasha, 2006, cap. 1; Luque, 2017, 2018). Veamos lo que dicen ambos autores sobre la selección natural, y cómo se relacionan sus ideas. Sea $p$ un rasgo fenotípico concreto de los individuos de una población $\mathrm{P}, p_{i}$ el valor del rasgo en el individuo i en P, $w_{i}$ la eficacia absoluta (absolute fitness) del individuo i en $\mathrm{P}, w$ la eficacia promedio (average fitness) de los individuos en $\mathrm{P}, \mathrm{y} h$ la heredabilidad del rasgo. ${ }^{3}$ En este contexto, se afirma que habrá selección natural ${ }^{4}$ entre los individuos de $\mathrm{P}$ siempre que:

3 El término «individuo» se usará como biológicamente neutral, como «forma de organización», pudiendo sustituirse en casos concretos por gen, gameto, organismo, colonia, holobionte, etc. Toda la formulación que ahora sigue, por tanto, debe entenderse como aplicable a varias formas de organización biológica.

4 Nótese que hablo de selección natural, no de evolución por selección natural. Ambos fenómenos son diferentes, como explicaré después en esta misma sección. 
(a) Haya diferencias fenotípicas entre ellos, $\operatorname{Var}\left(p_{i}\right)>0$;

(b) Dichas diferencias fenotípicas estén relacionadas sistemáticamente a diferencias con respecto a la eficacia biológica, $\operatorname{Cov}(w, p) \neq 0$;

(c) Dichas diferencias fenotípicas sean heredables, $h>0.5$

Las afirmaciones $(\mathrm{a})$ - (c) describen el esqueleto «lógico ${ }^{6}$ de la selección natural, es decir, las condiciones mínimas que deben darse para que esta ocurra. A partir de dicho esqueleto, Lewontin argumentaba que es esperable observar los efectos de la selección natural en diferentes niveles o formas de organización de la jerarquía biológica: genes, gametos, organismos, colonias, comunidades e, incluso, ecosistemas (Lewontin, 1970: p. 15). Lo único que se requiere es que tal forma de organización biológica sea lo suficientemente estable como para que la variación continua de su fenotipo o de la base genética del mismo no haga imposible que se pueda seleccionar algo - lo que se recoge en (3) así como lo suficientemente inestable como para que pueda surgir cierta variación fenotípica que haga que algunos miembros de la población sean ligeramente diferentes de otros y por tanto la selección natural tenga material donde seleccionar — tal como se recoge en (1) (Clarke, 2013) - . De satisfacerse ambos requisitos, aquellos rasgos ligados a la eficacia biológica de dicha forma de organización se verán afectados por el proceso de selección natural.

Asimismo, dicho esqueleto es la base sobre la que se introduce la matematización de la selección natural debida a Price — conocida habitualmente como «ecuación de Price $\gg-{ }^{7}$ que se utiliza para cuantificar la variación de rasgos fenotípicos concretos, $\Delta p$, en P:

(1) $\Delta p=b \operatorname{Cov}\left(w_{i}, p_{i}\right) / w+\mathrm{E}\left(w_{i}, \Delta p_{i}\right) / w$

El primer término del lado derecho de $(1), b \operatorname{Cov}\left(w_{i}, p_{i}\right) / w$, representa la covarianza entre los valores del rasgo en la población y las correspondientes eficacias, es decir, la variación del valor medio del rasgo $p$ en $\mathrm{P}$ atribuible al efecto de la selección natural. El segundo término, $\mathrm{E}\left(w_{i}, \Delta p_{i}\right) / w$, representa el valor esperado de lo que cambiaría el valor medio del rasgo $p$ en $\mathrm{P}$ si no hubiera ningún efecto debido a la selección natural, es decir, el cambio en el valor medio de $p$ en $\mathrm{P}$ debido únicamente a la existencia de sesgos de transmisión (por ejemplo: transmisión imperfecta, mutaciones, etc.).

5 En el trabajo original aquí citado, Lewontin afirmaba que la eficacia biológica es lo que tiene que ser heredable. Sin embargo, eso es erróneo, como el propio Lewontin observó (1985: p. 76). Lo que debe ser heredable es el rasgo fenotípico, no la eficacia biológica conferida por el rasgo. Ver también Godfrey-Smith (2009), Gildenhuys (2019).

6 «Lógico», en tanto que Lewontin no presupone ningún mecanismo que deba canalizar fenómenos tales como la heredabilidad, o el modo en que deben expresarse las diferencias fenotípicas (Okasha, 2006; Clarke, 2013).

7 Técnicamente, lo que aquí se presenta es la ecuación de Price en su versión de la teoría de la selección multinivel (MLS), pues de ella se sigue la discusión de las unidades de selección de manera directa. Otra posible manera de estudiar el problema es la teoría de la selección de tipos (kin selection) desarrollada por Hamilton (Sober \& Wilson, 1998; Goodnight, 2005, 2015; Okasha, 2014; Kramer \& Meunier, 2016). Esta última teoría, además, aunque matemáticamente equivalente a MLS, es causalmente inadecuada para captar el fenómeno de la evolución hologenómica (Okasha, 2014; Díaz, 2015). Por eso, ignoraré esa opción aquí. 
En vista de (1), pueden deducirse las siguientes observaciones:

(a) Habrá selección natural entre los individuos de una población cuando y solo cuando $h \operatorname{Cov}\left(w_{i}, p_{i}\right)>0 .{ }^{8}$ Dicho de otro modo, existirá selección natural en favor de un rasgo fenotípico heredable si y solo si hay una asociación causal entre la eficacia $w_{i}$ de los individuos que portan el rasgo, y el rasgo concreto.

(b) Que la selección natural esté dándose en una población P no implica necesariamente que haya evolución por selección natural en $\mathrm{P}$, ya que sus efectos se anularán cuando $h \operatorname{Cov}\left(w_{i}, p_{i}\right)=\mathrm{E}\left(w_{i}, \Delta p_{i}\right)$; en estos casos, habrá selección natural si se cumple la condición $(\mathrm{a})$, pero no se observará evolución por selección natural. ${ }^{9}$

En adelante, por tanto, me centraré únicamente en el primer término del lado derecho de la ecuación de Price, $h \operatorname{Cov}\left(w_{i}, p_{i}\right) / w$, al hablar de selección natural, ya que de ella se desprende la discusión ontológica - es decir, qué tipos de unidades de selección existenacerca de los niveles de selección (Okasha, 2006; Lloyd, 2017a).

\subsection{LA DISTINCIÓN ENTRE UNIDADES DE SELECCIÓN COMO INTERACTORES Y COMO REPRODUCTORES}

Los filósofos de la biología han distinguido entre dos tipos de unidades o niveles de selección: los interactores y los reproductores. ${ }^{10}$ Tal distinción se sustenta en la combinación de la estructura de la selección natural presentada en la sección previa con dos observaciones fundamentales sobre el mundo biológico:

(a) En la naturaleza, los individuos biológicos no aparecen habitualmente aislados, sino relacionados entre sí en grupos de interacción con efectos sobre su eficacia biológica esperada (fitness-affecting interactions) (Sober \& Wilson, 1998) (Figura 1).

(b) En la naturaleza parecen existir diferentes grados de cohesión entre grupos de individuos, y parece que la evolución ha hecho que ciertos grupos de individuos previamente existentes pierdan parte de su independencia reproductiva al formar grupos a una escala superior de la jerarquía biológica — por ejemplo, en especies con división del trabajo reproductivo como los organismos eusociales, o como los organismos pluricelulares (Buss, 1987; Maynard-Smith \& Szathmáry, 1995; Calcott \& Sterelny, 2011; Moreno \& Mossio, 2015)—.

8 En realidad, también habrá selección natural, pero contra el rasgo en vez de a su favor, si $h \operatorname{Cov}\left(w_{i}, p_{i}\right)<0$. Por cuestiones de parsimonia, no he considerado esta posibilidad aquí. Gracias a un revisor anónimo por esta observación.

9 Este último punto es técnicamente más complicado, ya que podría argumentarse que sí hay evolución por selección natural, que es precisamente lo que causa que la distribución del rasgo en la población no cambie pese al sesgo de transmisión contra el rasgo (Vrba and Gould, 1986; Maynard-Smith, 1987, 1991). Dejaremos este caso al margen.

10 Aunque originalmente se hablaba de replicadores y no de reproductores, en especial a raíz de los trabajos de Dawkins (1976) y Hull $(1980,1988)$, el concepto de replicador ha sido sustituido por el de reproductor o individuo Darwiniano en discusiones más recientes (Griesemer 2000; Godfrey-Smith 2009; Lloyd 2017a). No es este el lugar de explicar las razones para tal cambio de nomenclatura. 

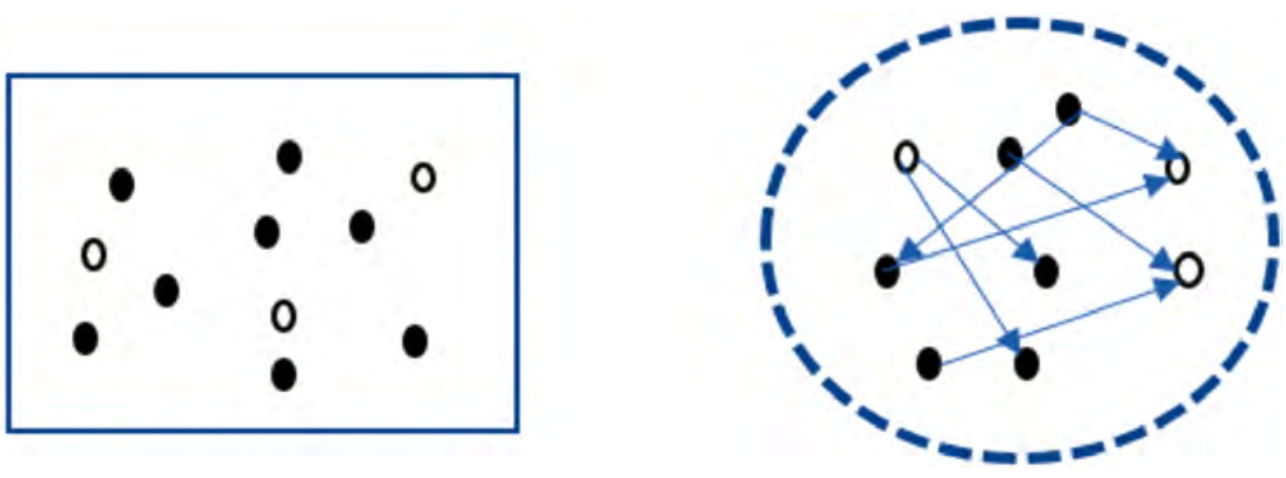

Figura 1

Grupo de individuos (representados por los círculos blancos y negros) interactuando de una manera tal que afecta a su eficacia reproductiva esperada si fueran individuos independientes (derecha, bajo la elipse punteada), en contraste con un grupo de individuos que no interactúa en maneras que afectan a su eficacia (izquierda, encerrados en un rectángulo).

Las flechas representan de manera abstracta tales interacciones, cuya especificación biológica queda siempre abierta a investigación empírica.

De la combinación de (a) y (b), junto con la observación de que las interacciones entre organismos con efectos sobre la eficacia biológica esperada de los mismos tienen carácter gradual, se sigue que:

(c) Es probable que la pérdida de la capacidad reproductiva y su delegación en otras entidades haya ocurrido de forma gradual, como consecuencia de la evolución de interacciones con efectos sobre la eficacia biológica esperada entre individuos previamente independientes.

Esto nos lleva a la observación de que hay al menos dos maneras de entender el concepto de heredabilidad y, en consecuencia, al menos dos tipos de unidades de selección ontológicamente diferentes (Figura 2): ${ }^{11}$

${ }^{11}$ El hecho de que me refiera a ellos como interactores y reproductores se debe a que quiero enfatizar el carácter ontológico de la distinción. No obstante, la distinción corresponde a lo que en la teoría de la selección multinivel se denominan teoría selección multinivel 1 (MLS1) y teoría selección multinivel 2 (MLS2), respectivamente (Damuth \& Heisler, 1988; Okasha, 2006; Lloyd, 2017a). Como es bien sabido, si la distinción se traza en términos de MLS1/MLS2 se suele decir que en MLS1 la unidad focal es el individuo y cómo cambia la distribución de los tipos de individuos transgeneracionalmente, mientras que en MLS2 la unidad focal es el grupo y, por tanto, el interés es en ver cómo los grupos actúan como progenitores de otros grupos. 


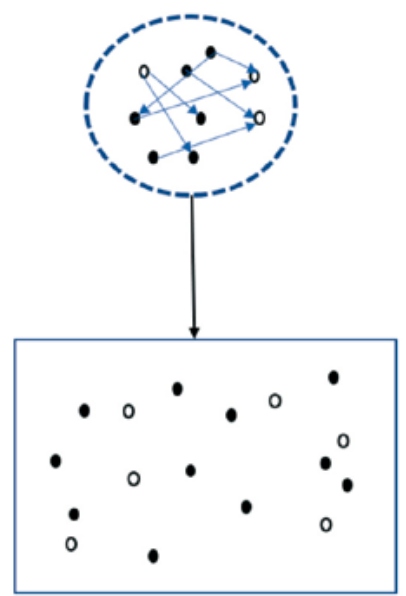

Figura 2

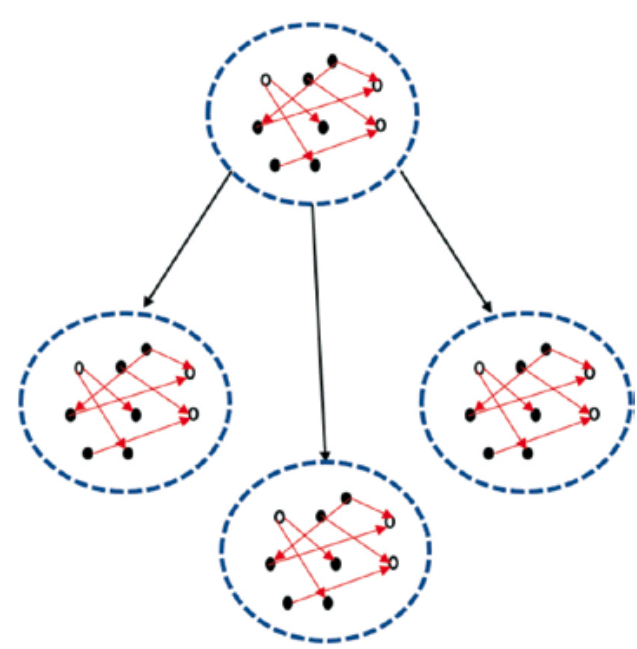

Dos maneras de entender la heredabilidad, donde las flechas negras representan eventos reproductivos.

A la izquierda, un grupo de individuos interactuando de una manera tal que afecta a su eficacia reproductiva esperada si fueran individuos independientes (interactor) dando lugar a una nueva distribución de partículas en la población global tras un evento reproductivo. A la derecha, un grupo de individuos actuando como reproductor, es decir, dando lugar a otros grupos de individuos con la misma estructura biológica que el progenitor.

(Interactores) Grupos de individuos (o partículas) relativamente estables y con fronteras más o menos definidas que interactúan entre sí y con el ambiente de forma tal que su eficacia biológica esperada - entendida como su reproducción - es diferente de la que cada una de tales partículas tendría si actuase en solitario. En los interactores, la heredabilidad se predica de cada uno de los individuos que componen el grupo, pero no de los grupos, pues son los primeros los que forman linajes progenitor-descendiente.

(Reproductores) Grupos que forman linajes progenitor-descendiente y, por tanto, de los que se predica la heredabilidad de manera directa. Dichos linajes progenitor-descendiente dan lugar a una similitud directa entre progenitores y descendientes; es decir, la similitud debida a parte de la variación fenotípica de los descendientes se debe a ser descendientes de sus progenitores y no de otros progenitores en la población — ver ecuación (1)—.

Esta distinción se aplica a diferentes niveles de la organización biológica, para los que se puede afirmar incluso que son a la vez un reproductor y un interactor con respecto a diferentes rasgos. Una manera de entender esto de forma menos abstracta es pensando en el caso de los organismos pluricelulares. Un organismo pluricelular, como el ser humano, es un interactor con respecto a su material genético, pues la reproducción de este depende en último término de la supervivencia y capacidad para encontrar pareja reproductiva de aquel. Esto causa que la reproducción de nuestro propio material genético sea diferente a como lo sería si no dependiese de la supervivencia y reproducción humana para asegurar su propia supervivencia. Al mismo tiempo, se puede considerar que los seres huma- 
nos somos reproductores, pues formamos linajes de progenitor-descendiente en virtud de nuestra capacidad de transmitir nuestras células sexuales. Una demostración de que somos reproductores es que han evolucionado varios mecanismos biológicos (el sistema inmunológico, la separación entre células sexuales y células somáticas, etc.) para garantizar que la selección natural que actúa entre los genes de nuestras células somáticas no cancele la selección natural a través de diferentes generaciones humanas (Godfrey-Smith, 2009; Clarke, 2013; Sterner, 2015; Stencel, 2016). En consecuencia, esto hace que la evolución de ciertos rasgos fenotípicos humanos dependa de nuestro carácter tanto como interactores como reproductores. Nótese, por tanto, que la distinción entre interactores y reproductores no es categórica y absoluta — como pensaban Dawkins y Hull, quienes acuñaron la distinción-, sino relativa a los rasgos cuya evolución se ha de explicar, y de forma gradual.

Otra forma de expresar la misma distinción entre interactores y reproductores, que será relevante para lo que diré después, es la siguiente. Imaginemos un escenario en que existen individuos $i$ con capacidad reproductiva y grupos de dichos individuos $k$ que se forman por mecanismos de afinidad biológica de cierto tipo. En dicho escenario, y utilizando lo que había presentado en la ecuación (1), caben tres posibilidades:

(2) $\operatorname{Cov}\left(w_{i}, p_{i}\right)=1 ; \operatorname{Cov}\left(w_{k}, p_{k}\right)=0$

(3) $\operatorname{Cov}\left(w_{i}, p_{i}\right)=0 ; \operatorname{Cov}\left(w_{k}, p_{k}\right)=1$

(4) $1>\operatorname{Cov}\left(w_{i}, p_{i}\right)>0 ; 1>\operatorname{Cov}\left(w_{k}, p_{k}\right)>0$

Es decir, que todo el proceso selectivo tenga lugar a nivel individual y nada al nivel del grupo (2), que todo el proceso selectivo ocurra a nivel del grupo y nada al nivel del individuo (3), o que se dé una situación intermedia (4). En la situación (2) se dice que el individuo es un reproductor; en la situación (3), el grupo es el reproductor; por último, en la situación (4) se dice que el individuo es un reproductor y el grupo un interactor. ${ }^{12} \mathrm{La}$ evolución de mecanismos concretos (separación entre células somáticas y células sexuales, sistema inmunológico, existencia de un cuello de botella en el proceso de desarrollo, mecanismos estables de adquisición horizontal de microorganismos, etc.) que cancelen o reduzcan los efectos de la selección individual en favor de la selección a nivel del grupo es una condición necesaria para que pueda la situación intermedia descrita por (4) (Godfrey-Smith, 2009; Clarke, 2014; Sterner, 2015).

Esto explica que el debate sobre las unidades de selección sea muchas veces un debate sobre causalidad, lo cual le da precisamente relevancia filosófica (Okasha, 2006): ¿es tal o cual forma de organización lo suficientemente estable y lo suficientemente inestable como para que la selección natural pueda actuar sobre ella? ¿De qué depende que lo sea o no? ¿Cuáles son los mecanismos biológicos que permiten alcanzar el mínimo grado de estabilidad necesario para que una forma de organización sea un interactor? ¿Y un reproductor?

12 Esto es técnicamente algo más complicado, pues en la situación (4) también pueden analizarse propiedades del grupo que lo hagan comportarse como reproductor, cuando se lo analiza en el contexto de competición con otros grupos. Esto será apropiado para estudiar determinados rasgos del grupo, cuya variación transgeneracional dependa del carácter del grupo como reproductor. Esta observación será especialmente relevante en la sección 4. Véase también Wade (2016), Lloyd (2017a) y Suárez \& Stencel (2020). 
Hechas estas aclaraciones solo cabe añadir las siguientes observaciones:

(a) En los procesos de selección natural habrá siempre interactores y reproductores, y esos dos niveles ontológicos no tienen por qué estar necesariamente anidados - a un mismo interactor pueden corresponder varios reproductores, una entidad puede ser a la vez reproductor e interactor, etc.

(b) Parte de la tarea de los biólogos consistirá en averiguar en qué nivel ha ocurrido o está ocurriendo la selección natural de manera tal que haya llevado o esté llevando a que ciertos rasgos alcancen un equilibrio estable en la población.

(c) Parte de la tarea de los biólogos evolucionistas consistirá en entender cómo reproductores previamente independientes pueden agruparse, perder su independencia reproductiva y evolucionar en entidades a un nivel jerárquico superior.

\section{El concepto de evolución hologenómica}

El debate sobre las unidades de selección ha adquirido una dimensión especialmente relevante en los últimos años debido a la discusión acerca del carácter potencial de los holobiontes como unidades de selección. Un holobionte es una forma de organización biológica que resulta de la asociación entre un organismo pluricelular (animal o planta), en el rol de hospedero, junto con su microbioma simbiótico (Margulis, 1990, 1991; Rohwer et al., 2002). ${ }^{13}$ El microbioma se refiere al conjunto de microorganismos (fundamentalmente bacterias, pero también hongos, virus, etc.) que cohabitan simbióticamente junto con las células del organismo pluricelular (Marchesi \& Ravel, 2015). La evolución en las técnicas de detección de microorganismos durante las dos últimas décadas ha revelado que los organismos pluricelulares conviven con un número elevadísimo de microorganismos simbióticos, en algunos casos (como el humano) tan numeroso como las propias células somáticas (McFall-Ngai et al., 2013; McFall-Ngai, 2015; Bosch \& Miller, 2016).

A la anterior observación cabe añadir una serie de apreciaciones sobre el importante papel que tienen ciertos microorganismos al codificar algunos rasgos fenotípicos expresados por sus hospederos pluricelulares. Algunos ejemplos muy discutidos en la literatura incluyen el caso del calamar hawaiano (Euprymna scolopes) y su simbionte primario, Vibrio fischeri, responsable de la luminiscencia de su hospedero; los corales y sus simbiontes, incluyendo la famosa zooxantella, responsable de su coloración; el caso del ganado bobino y su microbiota intestinal, responsable de su capacidad para digerir celulosa; o el caso de los murciélagos vampiros, cuyo microbioma codifica la mayor parte de los genes que le permiten digerir la sangre. No es este el lugar de hacer una revisión exhaustiva de tales casos, pero la evidencia que indica que existe una conexión entre el microbioma y ciertos fenotipos de sus hospederos es abrumadora (para una revisión, ver Guerrero et al., 2013; Lavagnino et al., 2014; Lynch \& Hsiao, 2019). Asimismo, existe abundante evidencia que documenta que los fenotipos codificados por el microbioma afectan sustancialmente la eficacia bioló-

13 El concepto de «simbiosis» que se utilizará en este trabajo es, en consonancia con el concepto utilizado por los defensores del concepto hologenómico de evolución, neutral con respecto al carácter beneficioso (mutualismo), neutral (comensalismo) o perjudicial (parasitismo) de la asociación. En este sentido, se sigue la definición originalmente propuesta por de Bary (1879). 
gica del hospedero - y se sigue prácticamente de la afirmación anterior, toda vez que los fenotipos codificados por el microbioma suelen ser adaptaciones muy complejas, que podrían caracterizarse como ingenieriles, siguiendo la nomenclatura de Lloyd (1994; en prensa). No obstante, como argumentaré detalladamente en la sección 3, la existencia de esta evidencia y la afirmación de que los holobiontes son unidades de selección son dos tesis diferentes, aunque relacionadas.

Finalmente, existe innumerable evidencia que sugiere la existencia de ciertos canales o mecanismos que hacen posible la transmisión de los microorganismos que componen el microbioma de un hospedero progenitor a sus descendientes. Por ejemplo, los simbiontes de las células eucariotas se transmiten por herencia citoplasmática; los insectos transmiten sus endosimbiontes primarios verticalmente a través de sus bacteriocitos; algunos insectos (termitas) y mamíferos (koalas) transmiten sus simbiontes a través de sus sistemas de alimentación (coprofagia); a través del canal de parto, en el caso de muchas especies de mamíferos; por medio de adquisición ambiental; etc. (Zilber-Rosenberg \& Rosenberg, 2008; Bright \& Bulgheresi, 2010; Gilbert, 2014; Gilbert \& Chiu, 2015). Sin embargo, como mostraré en la sección 4, esta evidencia, aunque aparentemente persuasiva, puede enmascarar un error que haría injustificado inferir que los holobiontes son unidades de selección. $\mathrm{O}$, dicho de otro modo, mostrar que hay ciertos mecanismos de transmisión del microbioma, aun cuando incrementa la probabilidad de que los holobiontes actúen como un nivel de selección, no lo implica necesariamente, pues como veremos se requieren condiciones más estrictas.

Dado que la caracterización tradicional de las unidades de selección establece que una forma de organización biológica es una unidad de selección cuando muestra diferencias heredables en eficacia ligadas a rasgos fenotípicos, y dadas las observaciones previas sobre los holobiontes, los biólogos Zilber-Rosenberg y Rosenberg propusieron hace ya más de una década el concepto o teoría hologenómica de la evolución. Dicha «teoría» estipula que el holobionte debiera ser considerado una unidad de selección — «la unidad de selección más fundamental», en palabras de Dupré \& O’Malley (2009: p. 14, el énfasis es mío)—con su hologenoma actuando como reproductor (Zilber-Rosenberg \& Rosenberg, 2008; Rosenberg \& Zilber-Rosenberg, 2013, 2018)..$^{14}$

Resulta necesario en este punto esclarecer qué es el hologenoma. Si el holobionte se define como la unidad ecológica formada por un hospedero pluricelular (animal, planta) y todos los microorganismos que componen su microbioma, el hologenoma se define como la totalidad de la información genética que está codificada en el holobionte. Es decir, como la totalidad compuesta por el genoma del hospedero y el genoma de todos los microorganismos del microbioma.

La hipótesis ha sido ampliada, reformulada y defendida por diferentes investigadores desde que fuera originalmente descrita por Zilber-Rosenberg y Rosenberg. Entre los filósofos, cabe destacar el pionero trabajo de Dupré \& O’Malley (2009), los trabajos más recientes de Lloyd (2017b; Lloyd \& Wade, 2019), y los trabajos de Suárez \& Triviño (2019, 2020; Suárez, 2020). No es este lugar de entrar a valorar las diferentes propuestas específicas sobre el concepto hologenómico de evolución. Simplemente hay que señalar que el desacuerdo radica fundamentalmente en la delimitación de los microorganismos que in-

${ }^{14}$ Para entender los pormenores del origen histórico del concepto hologenómico de evolución, ver Suárez (2018) y Baedke et al. (2020). 
tegran el holobionte (Figura 3). Para algunos autores, el holobionte está constituido por el hospedero más la totalidad de su microbioma caracterizado taxonómicamente, incluyendo microorganismos transitorios (e.g. Zilber-Rosenberg \& Rosenberg, 2008; Gilbert et al., 2012, 2017; Rosenberg \& Zilber-Rosenberg, 2013; Bordenstein \& Theis, 2015; Theis et al., 2016). Para otros, en cambio, la parte del microbioma que constituye una unidad de selección junto con el hospedero sería el conjunto de microorganismos taxonómicamente delimitados y que muestra un patrón de divergencia filogenética - denominado patrón filosimbiótico (phylosymbiosis) - con el hospedero (e.g. Brucker \& Bordenstein, 2012, 2013a, 2013b; Brooks et al., 2016). Un tercer grupo de autores defiende que el factor más relevante es la persistencia de la asociación simbiótica durante la vida del hospedero y, por tanto, la parte del microbioma que constituye el holobionte como unidad de selección se reduciría a los microorganismos residentes — al margen de si muestra o no un patrón de divergencia filosimbiótica con el hospedero- (e.g. Roughgarden et al., 2018; Lloyd, 2017b; Rosenberg \& Zilber-Rosenberg, 2018; Lloyd \& Wade, 2019; Roughgarden, 2020). Finalmente, un grupo creciente de investigadores defiende que la parte del microbioma que constituye el holobionte como nivel de selección es la parte funcional o genética, más bien que taxonómica (e.g. Taxis et al., 2015; Doolittle \& Booth, 2017; Lemenceau et al., 2018; Suárez \& Triviño, 2019; Suárez, 2020). ${ }^{15}$

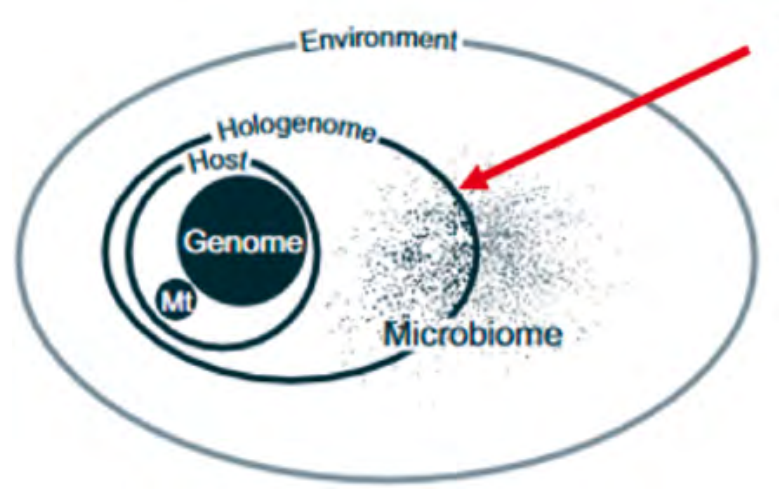

¿Cómo trazar el límite?

Figura 3

Delimitación de los componentes de holobionte/hologenoma. El debate está en determinar los criterios biológicos para trazar la línea que decide los componentes de microbioma que se consideran constitutivos del holobionte/hologenoma de aquellos que no.

De Brucker \& Bordenstein (2013a: p. 261, Fig. 1).

Hasta ahora, se ha presentado la evidencia empírica que sugiere que sería posible considerar el holobionte/hologenoma como una unidad de selección, pero no se ha explicado de manera exhaustiva cuáles serían las implicaciones de tal hipótesis, ni cómo debe concebirse. En las siguientes secciones, pues, se argumentará que el holobionte/hologenoma es un nivel de

15 Para una revisión completa de estas alternativas y sus similitudes/diferencias, ver Suárez (2018). 
selección tanto en su forma de interactor - ecuación (2) - como en su forma de reproductor - ecuación (3) - al menos para algunos taxones de animales y de plantas, y se detallarán algunas de las implicaciones biológicas de dicha hipótesis. En virtud de tal elaboración, argumentaré, el concepto hologenómico de evolución está perfectamente justificado en una forma restringida.

\section{El holobionte/hologenoma como interactor}

Como dije en la sección 1.1., la clave para que un grupo de organismos pueda considerarse un interactor es que los organismos estén relacionados entre sí y con el ambiente de forma tal que su eficacia biológica esperada — entendida como su reproducción - sea diferente de la que cada uno de tales individuos tendría si actuase en solitario (Sober \& Wilson, 1998; Okasha, 2006; Lloyd, 2017a). La clave, por tanto, es justificar que eso ocurre de hecho en el holobionte.

Algunos autores críticos con el concepto hologenómico de evolución argumentan que tal condición no se da salvo en muy raras ocasiones, y nunca para la totalidad del microbioma, sino a lo sumo para una o dos especies (Moran \& Sloan, 2015; Douglas \& Werren, 2016; Queller \& Strassmann, 2016; Skillings, 2016). ${ }^{16}$ Su argumento es más o menos el siguiente: por un lado, aunque cabe atribuir efectos fenotípicos aparentemente impresionantes al microbioma, no cabe inferir de tales observaciones el hecho de que la totalidad del microbioma codifique tales rasgos. La tarea del biólogo es más bien descubrir qué especie o especies están causando tales efectos fenotípicos. Recurrir a la totalidad del microbioma es una imprecisión que puede inducir a confusión y, sobre todo, a no detectar el agente causal real del efecto fenotípico. Puesto de otro modo: del hecho de que organismos pluricelulares con su microbioma expresen un carácter fenotípico (ver Lynch \& Hsiao, 2019 para ejemplos) no se infiere que todo el microbioma sea la base genética que codifica dicho carácter, sino que dicho carácter debe estar codificado por un microorganismo de una especie concreta, del que sí cabría argumentar -si la unión entre hospedero y simbionte satisface otros criterios- que constituye un interactor junto con su hospedero (ver también Chandler \& Turelli, 2014; Bourrat \& Griffiths, 2018).

Pero el argumento no se agota ahí. Moran \& Sloan (2015) y Douglas \& Werren (2016) van un paso más allá y critican lo que ellos perciben como un enorme error en la concepción hologenómica de la evolución. En su visión, ninguno de los argumentos presentados por los defensores de la hipótesis logra demostrar que el microbioma sea algo más que un mero ambiente al que se adapta o se ha adaptado su hospedero, siendo este último el verdadero interactor. Este argumento constituye una crítica muy sólida al concepto hologenómico de evolución, y requiere entenderse bien. Lo que Moran \& Sloan (2015) y Douglas \& Werren (2016) están tratando de mostrar es que toda la evidencia acerca del papel del microbioma en el desarrollo de su hospedero o en su funcionamiento, toda la información acerca de los patrones paralelos de divergencia filogenética (filosimbiosis), o incluso sobre la intimidad de las asociaciones entre hospederos y sus microbiomas son perfectamente ex-

${ }^{16}$ Cabe destacar que tanto Moran, como Werren y como Douglas son destacados investigadores de los efectos simbióticos sobre sistemas animales (e.g. Moran, 2006; Werren et al., 2008; Douglas, 2010), por lo que su crítica al carácter del hologenoma como nivel de selección no está hecha desde una perspectiva abiertamente crítica con el posible carácter evolutivo de la simbiosis. 
plicables como patrones de co-diversificación ecológica entre diferentes especies que evolucionan de manera independiente. Los efectos observados en el hospedero serían, en consecuencia, los efectos habituales de la adaptación del hospedero a cualquier tipo de ambiente. Pero carece de sentido argumentar que se trata de efectos derivados del hecho de que el hospedero y su microbioma se relacionan entre sí de forma tal que su eficacia biológica esperada - entendida como su reproducción - es diferente de la que cada una de tales partículas tendría si actuase en solitario. Todos estos procesos son, en consecuencia, evolutivos solo de manera aparente, pues en realidad en la mayoría de los casos resultan de los efectos no evolutivos de filtración ecológica (ecological filtering) ${ }^{17}$, cosa que es fácil de mostrar al apreciar que la mayor parte de microorganismos que conforman el holobionte también pueden vivir libremente (Moran \& Sloan, 2015, p. 4, Fig. 1).

Este punto puede ilustrarse con un ejemplo que, aunque no exactamente equivalente, es suficientemente satisfactorio para ver la crítica con claridad. El argumento ha sido elaborado por Bourrat \& Griffiths (2018) como crítica a los argumentos empleados para defender el concepto hologenómico de evolución. ${ }^{18} \mathrm{Su}$ argumento se desarrolla como sigue: es bien sabido que las propiedades de muchos animales han evolucionado a su estado actual debido a que el campo gravitatorio terrestre vale aproximadamente $9,8 \mathrm{~ms}^{-2}$. Si el campo gravitatorio tuviese un valor diferente, es probable que los organismos tuvieran un fenotipo diferente, bien sea porque habrían evolucionado de maneras diferentes, o porque su proceso de desarrollo los hubiera llevado a expresar características distintas (e.g. extremidades exageradamente más largas). En este sentido, el campo gravitatorio terrestre parece jugar un papel análogo para ciertos taxones animales al que juegan muchos microorganismos del microbioma. Por tanto, cabría concluir que los hospederos, junto con el campo gravitatorio, constituyen un único nivel de selección como interactor. Pero eso es absurdo o, en su defecto, es totalmente contrario a la práctica biológica. Luego, bajo el mismo tipo de razonamiento, se llega a la conclusión de que tampoco cabe considerar a los microorganismos del microbioma parte de un único interactor junto con su hospedero.

Aunque estos argumentos son persuasivos y en parte correctos, enmascaran un equívoco, a saber: que los procesos de adaptación a ambientes no genéticos o abióticos siguen la misma dinámica que los procesos de adaptación a ambientes genéticos o bióticos. Diferentes autores han argumentado que esto no es correcto (Drown et al., 2013; Drown \& Wade,

${ }^{17}$ Los procesos de filtración ecológica se producen cuando un organismo elige por razones meramente oportunísticas (es decir, no ligadas a la historia de selecciones previas de los organismos de su linaje) ciertos factores bióticos de entre aquellos que tiene a su disposición en el ambiente. Estos procesos contrastan con los casos de filtración evolutiva, en que la elección se debe principalmente a factores histórico-genéticos que han sido heredados de los progenitores. Parte de la tarea en biología consiste en determinar qué comportamientos o rasgos son resultados de la historia evolutiva del linaje, y cuáles son resultados de la mera oportunidad que se le ofrece a los organismos.

${ }^{18}$ Es sorprendente observar que Griffiths sea coautor del trabajo con Bourrat, ya en que en trabajos anteriores había utilizado exactamente el mismo ejemplo para argumentar que la totalidad del sistema de desarrollo (developmental system) de un organismo -incluidos elementos abióticos del ambientedeberían considerarse parte de la unidad de selección (Griffiths \& Gray, 1994, 1997; Griffiths \& Hochman, 2015). Es más, el propio Griffiths, en comunicación personal, admite que no ve problemas en considerar la totalidad del sistema de desarrollo — incluido el microbioma - como unidad de selección. 
2014; Stencel \& Proszewska, 2017; Osmanovic et al., 2018; Suárez \& Triviño, 2019; Triviño \& Suárez, 2020), aunque quienes mejor han expresado esta idea han sido Lloyd \& Wade (2019) y, por tanto, expondré sus argumentos aquí. El razonamiento es bastante simple: cuando una determinada forma genética - pongamos por caso, los alelos que codifican un determinado fenotipo- evoluciona hacia el equilibrio estable en que los vemos hoy como consecuencia de un efecto ambiental no genético (e.g. el campo gravitatorio), su evolución no afecta en modo alguno a la distribución del efecto ambiental no genético que causó su evolución. O, dicho de manera menos abstracta, la evolución de nuestras extremidades hasta alcanzar la longitud que tienen hoy día no afectó en modo alguno al campo gravitacional terrestre, que fue siempre de $9,8 \mathrm{~ms}^{-2}$, antes de la evolución de nuestras extremidades, durante su proceso de evolución, y tras su evolución. La dirección de la «flecha» causal es clara.

Esto último puede verse matemáticamente de un modo muy sencillo, en conexión con la ecuación (1) (lo que sigue viene de Lloyd \& Wade, 2019, pp. 155-156, y a su vez de Drown et al., 2013; Drown \& Wade, 2014). Sea $p_{b}$ un rasgo en un hospedero que incrementa su eficacia en un factor $s$ en un ambiente $E_{l}$, pero que es neutral en un ambiente $E_{2}$. Supongamos que $f_{l}$ representa la frecuencia de $E_{l}$, e imaginemos que el hospedero está distribuido azarosamente en los diferentes ambientes. Siendo esto así, y asumiendo que no existe sesgo de transmisión, el rasgo $p_{b}$ incrementará transgeneracionalmente de acuerdo con la fórmula:

(5) $\Delta p_{b}=\left(s f_{1}\right)\left(p_{b}\right)\left(1-p_{b}\right) / w_{\text {bospedero }}$

Donde $w_{\text {hospedero }}$ representa la eficacia biológica media del hospedero, $1+s f_{1} p_{b}$. De aquí se deduce que $p_{h}$ incrementará su presencia en la población P siempre que $f_{l}>0$, mientras que no evolucionará en caso contrario. Es importante además señalar que $p_{h}$ tardará tanto o más en incrementar su presencia en $\mathrm{P}$ cuanto menor sea $f_{l}$. Pero lo más importante de este caso es que lo que incremente $p_{b}$ es causalmente irrelevante para $f_{l}$, cuya presencia se mantendrá inalterada o, si varía, lo hará por otros factores diferentes al incremento de $p_{h}{ }^{19}$

Considérese ahora una situación distinta, en la que el hospedero se adapta a un ambiente genético, como puede ser la presencia de un simbionte. Sea ahora $p_{m}$ el rasgo del microbio que incrementa la eficacia del hospedero en un factor $s$. Supongamos que entre hospedero y microbio existe una relación epistática que hace que ambos se estimulen mutuamente en su proceso selectivo. Sea pues $t$ el factor selectivo que incrementa la frecuencia de $p_{m}$ cuando este se encuentra en presencia de $p_{b}$. Supongamos que el hospedero y los microbios se asocian de manera azarosa — es decir, no hay afinidades selectivas - en tal escenario. La variación en la frecuencia de $p_{h} \mathrm{y}$ de $p_{m}$ vendrá dada por el siguiente par de ecuaciones:

(6) $\Delta p_{b}=\left(s p_{m}\right)\left(p_{b}\right)\left(1-p_{b}\right) / w_{\text {hospedero }}$

(7) $\Delta p_{m}=\left(t p_{h}\right)\left(p_{m}\right)\left(1-p_{m}\right) / w_{\text {microbio }}$

Donde $w_{\text {hospedero }}$ representa la eficacia biológica media del hospedero, $1+s p_{m} p_{b}, \mathrm{y} w_{\text {microbio }}$ representa la eficacia biológica media del microbio, $1+t p_{h} p_{m}$. En este escenario, a diferencia de lo que ocurría en el escenario representado en (5), la frecuencia de los ambientes genéticos entrará en una dinámica de reforzamiento mutuo (runaway) que hará que ambos «am-

${ }^{19}$ Naturalmente, este modelo asume que no hay efectos derivados de la construcción de nicho (niche construction), o que, de existir, son despreciables. Acéptese esa asunción por parsimonia. 
bientes» se hagan más abundantes de forma recíproca. Este escenario, por tanto, representa perfectamente una situación en que la asociación entre hospedero y microbio puede, $y$ debe, considerarse un interactor, de acuerdo con la definición que he introducido en la sección 1.1. Nótese, además, que el proceso de reforzamiento mutuo al que he hecho alusión se produce pese a la inexistencia de afinidades selectivas entre hospedero y microbio. Esto sugiere que estas no son biológicamente previas a que estas asociaciones puedan ser consideradas interactores, sino más bien al revés. Lo que este argumento presupone, en cambio, es la existencia de cierto grado de epistasis entre hospedero y microbio, elemento cuya necesidad se prueba también en otros modelos (Bourrat, 2019). ${ }^{20}$

Lo que el argumento de Lloyd \& Wade prueba, pues, es que la adaptación a ambientes abióticos no es isomorfa desde el punto de vista evolutivo a la adaptación a ambientes genéticos, puesto que solo en la segunda, pero no en la primera, pueden darse relaciones epistáticas que alteren la naturaleza del proceso. Por tanto, el argumento de Moran \& Sloan (2015) y Douglas \& Werren (2016) no es estrictamente válido, y mucho menos lo es el elaborado por Bourrat \& Griffiths (2018). Ahora bien, creo que Lloyd \& Wade (2019) no han sabido apreciar en su totalidad la fuerza del argumento contrario a la idea de que el holobionte sea una unidad de selección como interactor. Así pues, su argumento, aunque esencialmente correcto, no da cuenta de una de las objeciones principales elaborados por los críticos del concepto hologenómico de evolución, a saber: que aun cuando los procesos de adaptación a ambientes bióticos y abióticos no sean isomorfos, hay una diferencia sustancial entre el proceso que experimenta el hospedero y el que experimentan los simbiontes que hace que la situación no sea equivalente para ambos. Esto es claro cuando se aprecia que la mayor parte de los microorganismos que forman el microbioma de un hospedero de una especie determinada pueden convivir con diferentes hospederos, así como vivir libremente (Suárez \& Stencel, 2020). Asimismo, en caso de muerte de su hospedero, pueden migrar a otros hospederos, no viéndose su eficacia biológica alterada en ningún sentido, aun cuando existan las interacciones epistáticas de las que Lloyd \& Wade hablan. Al ser esto así, el argumento de Lloyd \& Wade, aunque esencialmente válido, pierde mucha fuerza, ya que no es para nada claro que la eficacia biológica esperada de los simbiontes sea diferente de la eficacia que cada uno de ellos tendría si actuase en solitario que, recordemos, era la clave para defender que una forma de organización biológica constituye un interactor. ${ }^{21}$

Toda esta discusión hace que nos encontremos, pues, con un dilema: por un lado, hay que dar cuenta de la diferencia entre el caso del holobionte y el caso de la adaptación a un

20 La presunción según la cual hospedero y simbiontes interactúan epistáticamente es legítima en vista del tipo de relación biológica existente entre ambos, tal y como he descrito en la sección 2 (ver Guerrero et al., 2013: Lavagnino et al., 2014; Lynch \& Hsiao, 2019). Tal relación, de hecho, ha llevado a algunos autores a defender la consideración del holobionte/hologenoma como un individuo biológico en diferentes sentidos: inmunológico (Pradeu, 2010, 2016, 2020; Gilbert \& Tauber, 2016), fisiológico (Dupré \& O’Malley, 2009; Godfrey-Smith, 2013), etc. Al margen de la validez de estas otras formas no evolutivas de describir la individualidad biológica, lo que es relevante desde una perspectiva evolutiva es que todos estos casos sugieren la existencia de una relación epistática entre hospedero y simbionte. Por consiguiente, la asunción del modelo de Lloyd \& Wade no puede decirse que sea gratuita, o una mera posibilidad teórica, sino que está completamente justificada empíricamente.

21 Posiblemente tampoco la del hospedero, pero eso es más discutible dado que no se conocen hospederos sin simbiontes en la naturaleza. Ignoraré, por tanto, esa posibilidad. 
ambiente abiótico; por otro, hay que dar cuenta de la objeción de que no parece haber efectos diferenciales notorios sobre la eficacia esperada de los simbiontes, pese a existir tales efectos en la dirección del hospedero.

\subsection{El MOdELO DE LA ESTABILIDAd DE RASGOS}

Una manera de resolver el dilema anterior es adoptar la perspectiva de la estabilidad de rasgos recientemente elaborada por Suárez (2020), y primeramente esbozado en Suárez \& Triviño (2019). Dicha perspectiva se asienta en las siguientes observaciones empíricas:

(a) Las bacterias intercambian genes de manera frecuente en el proceso habitualmente conocido como transferencia genética horizontal (HGT, por sus siglas en inglés);

(b) Dicho intercambio se incrementa cuando su nicho es un microbioma dentro de un hospedero;

(c) Una misma especie o taxón de bacterias puede ser soporte genético de múltiples grupos funcionales, por lo que es equívoco asociar el grupo taxonómico a la función o funciones que este pueda codificar;

(d) El microbioma presenta habitualmente redundancia funcional, es decir, diferentes especies bacterias codifican los mismos rasgos fenotípicos — produciendo, por ejemplo, los mismos metabolitos y portando los mismos genes-;

(e) Aunque la composición taxonómica del microbioma de un determinado hospedero varíe sustancialmente, su composición funcional se mantiene relativamente estable.

(f) La composición genética del hospedero es mucho más estable que la composición genética de su microbioma, debido a condiciones específicas de los organismos eucarióticos que hacen que su genoma muestre menor variabilidad intra y transgeneracional.

Sobre la base de estas observaciones, Suárez (2020) elabora el siguiente argumento: el holobionte/hologenoma tiene una parte relativamente robusta (el hospedero), cuya composición genética se mantiene relativamente invariante dentro de una misma generación y transgeneracionalmente, y una parte más variable, el microbioma. Dicho microbioma debe caracterizarse de forma funcional, haciendo referencia a los grupos genéticos que están codificados por los microorganismos del microbioma, pero no de forma taxonómica (Suárez, 2016). Esto da lugar a una imagen del holobionte/hologenoma más como un genoma extendido que como un holo-genoma, imagen que contrasta con el resto de hipótesis de evolución hologenómica (Figura 4).

En virtud de esto, se argumenta que la clave de los procesos de selección hologenómica es que los microorganismos que componen el microbioma intercambian de manera libre ciertos componentes genéticos, lo que lleva a un crecimiento exponencial de la base genética de aquellos rasgos que benefician al hospedero. Dicho crecimiento exponencial se produce, precisamente, por el intercambio relativamente libre de genes que se da entre las diferentes especies de microorganismos que componen el microbioma, así como a los propios procesos selectivos dentro del microbioma (Figura 5). Esto lleva a que el hospedero no necesite incorporar esa base genética en su genoma y, por tanto, genomas relativamente poco adaptados a ciertos ambientes abióticos puedan sobrevivir pese a los obstáculos ambientales que tienen que afrontar. 

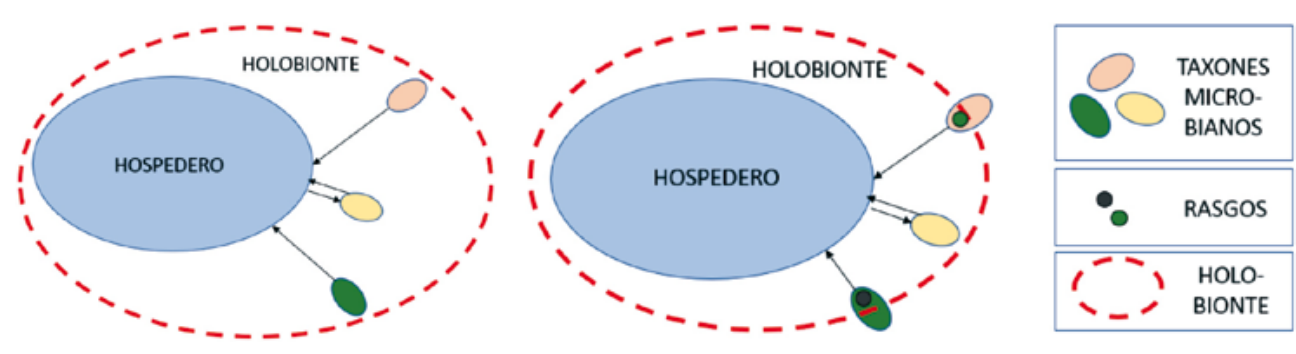

Figura 4

Comparación de modelos estándar de evolución hologenómica (izquierda) con el modelo de la estabilidad de rasgos (derecha). Las flechas representan relaciones simbióticas. Nótese que en el segundo los límites del holobionte están caracterizados funcionalmente. De Suárez (2020, pp. 15-16, Fig.4-5).
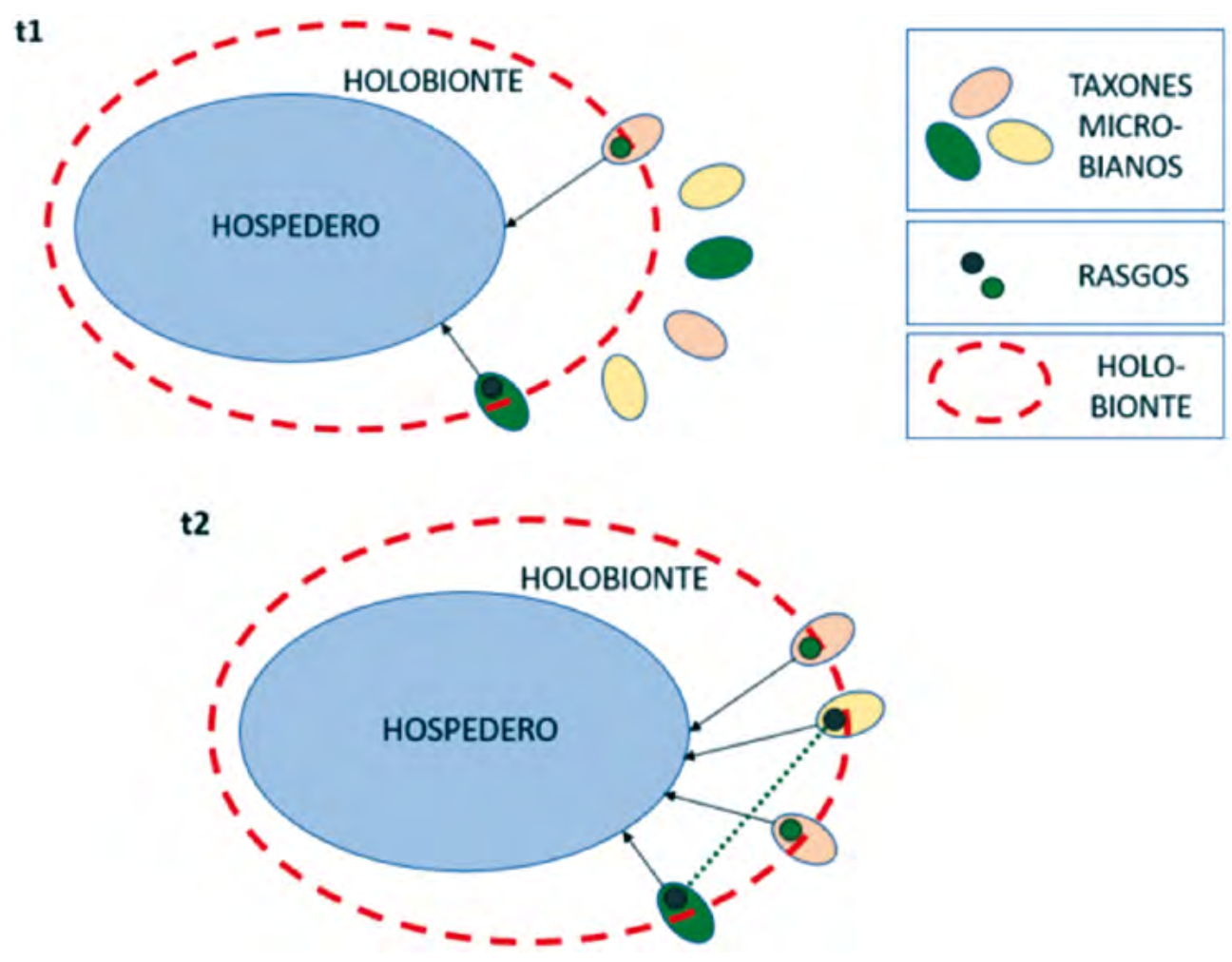

Figura 5

Ejemplificación del modelo de estabilidad de rasgos durante la ontogenia ( $\mathrm{t} 1-\mathrm{t} 2)$ de un hospedero. La línea punteada en $\mathrm{t} 2$ representa un evento de HGT que hace que la frecuencia de la base genética del rasgo asociado a la eficacia del hospedero aumente en otros linajes de microbios. De Suárez

(2020: p. 19, Fig. 6). 
Expresemos esta idea de otra forma, a saber: explicando cómo el modelo de la estabilidad de rasgos reformularía los argumentos de Lloyd \& Wade (2019) en favor de considerar el holobionte como interactor. Esta reformulación tiene especial interés, pues sirve para resolver la objeción planteada por Moran \& Sloan (2015) que, como dije, Lloyd \& Wade (2019) no habían logrado solucionar de manera satisfactoria. El argumento de Lloyd \& Wade (2019) se basaba en que el ambiente génico bacteriano incrementaría de acuerdo con lo descrito en la ecuación (7). Pero en realidad, esto no es exacto, pues los autores lo ligaban a la eficacia biológica del microbio que portaba los genes en interacción genética epistática con ciertos genes del hospedero. Lo que ocurre, más bien, es que tales genes del microbio tenderán a diseminarse a otros microbios del microbioma. Y esto es así precisamente por razones estrictamente evolutivas, pues si ocurriese lo que Lloyd \& Wade (2019) suponen se generarían constantemente las peligrosas «madrigueras evolutivas» (evolutionary rabbit hole) descritas por Bennet \& Moran (2015). Una madriguera evolutiva ocurre cuando dos linajes (un hospedero y un simbionte) que comparten beneficios simbióticos mutuos se unen dando lugar a simbiosis obligatorias con herencia vertical directa. En esos casos, ambos linajes se vuelven evolutivamente codependientes, lo que genera dinámicas poco esperables que incluyen fenómenos como la reducción genómica extrema en los simbiontes. El peligro de estas madrigueras es que, en último término, acaban por reducir el nicho ecológico de ambas especies. Esto hace que sean más vulnerables a sufrir una extinción mutua de lo que lo serían si viviesen como linajes independientes. Dicho de otro modo: asociaciones que inicialmente ampliaban sustancialmente el contenido genético de ambas especies, y por tanto su adaptabilidad, se transforman en su contrario con el consiguiente riesgo evolutivo para ambos linajes. En consecuencia, no se espera que la evolución favorezca este tipo de asociaciones, lo cual además se observa de forma empírica en diferentes sistemas biológicos, incluyendo los casos explicados en la sección 2 .

Ahora bien, el tipo de evolución que se da en el holobionte/hologenoma, según el modelo de la estabilidad de rasgos, permite que los microorganismos (y sus hospederos) obtengan el beneficio de vivir en el microbioma sin tener que pagar los costes evolutivos generados por las madrigueras evolutivas. Esto se debe al hecho de que la estructura biológica que se crea posibilita la aceleración de la HGT entre los linajes del microbioma, generando una redundancia funcional que no viene acompañada del secuestro de linajes de simbiontes. Se obtienen, pues, los beneficios de una asociación simbiótica temprana sin los riesgos de extenderla evolutivamente.

El interés de introducir el concepto hologenómico de evolución reside, por tanto, en explicar de manera adaptativa todos los procesos que ocurren dentro del microbioma, y que llevan al incremento de la eficacia biológica esperada - entendida como su reproducción- de la base genética que codifica rasgos beneficiosos para el hospedero, y del propio hospedero, siempre que este último tenga éxito en incentivar dichos efectos (Rudman et al., 2019; Roughgarden, 2020; Henry \& Ayroles, 2020). Estos efectos quedarían sin explicación adaptativa de no aceptarse la tesis de que el holobionte/hologenoma es un interactor. ${ }^{22}$

22 Naturalmente, cabría argumentar que esta manera de entender la evolución hologenómica presupone una visión adaptacionista de la evolución, la cual es cuestionable y ha sido criticada persuasivamente por diferentes autores (Lloyd, 2015, en prensa). Ahora bien, esa crítica sería solamente correcta toda vez que se asuma que todo rasgo holobióntico debe ser una adaptación, cosa que el modelo de estabilidad de rasgos no presupone. El modelo de estabilidad de rasgos se presenta para dar cuenta de algunos rasgos, no de todos los rasgos. 
Asimismo, el hecho de que los microbios que codifican rasgos fenotípicos beneficiosos para su hospedero puedan vivir en otros nichos quedaría inadecuadamente explicado si no se adopta el modelo de estabilidad de rasgos, pues daría la impresión de que, en efecto, no hay nivel de selección actuando a nivel del holobionte/hologenoma - ya que si son particulares a una sola especie de microbio, que también puede vivir en otros nichos, la base genética de tales rasgos habría sido seleccionada para ese microbio, y no para el holobionte/hologeno$\mathrm{ma}^{23}$

Una consecuencia importantísima del modelo de la estabilidad de rasgos es que la concepción hologenómica de la evolución lleva a hacer una distinción radical entre procesos simbióticos hospedero-simbionte que llevan a la coespeciacion (células eucarióticas, áfidos y $B$. aphidicola, etc.) y procesos que llevan a la coevolución entre el hospedero y una serie de rasgos cuya base genética es intercambiable entre diferentes especies de microrganismos. Nótese que este último fenómeno es específico de la evolución hologenómica, pues no se trata de una coevolución al uso — como la descrita por Lloyd \& Wade-, sino que va más allá, hasta el punto de, como argumentaré, que se pueda considerar al holobionte/hologenoma como reproductor.

\section{El holobionte/hologenoma como reproductor}

Falta ahora argumentar cuáles son las condiciones bajo las que el holobionte/hologenoma podría considerarse un reproductor. Recordemos que una forma de organización biológica es un reproductor solo si existe heredabilidad a su nivel específico y, en consecuencia, puede hablarse de la existencia de linajes progenitor-descendiente. Es decir, si $h \operatorname{Cov}\left(w_{i}, p_{i}\right) \neq 0$, a su nivel específico. Gran parte de los argumentos contra la concepción hologenómica de la evolución se asientan, de hecho, en esta observación, a saber: que no existe mecanismo alguno que garantice que los holobiontes formen linajes y, por tanto, incluso aunque en ocasiones se pueda hablar de su papel como interactores, es imposible afirmar que son reproductores.

La importancia de esta crítica es sustancial, ya que de ser correcta minaría por completo el leitmotiv de la concepción hologenómica de la evolución, tal cual fue presentado originalmente. Recordemos que la razón por la que se introduce es explicar el origen de ciertas adaptaciones en los hospederos que no se pueden explicar recurriendo unicamente a la información genética contenida en su genoma. Pero mostrar que los holobiontes/hologenomas son interactores difícilmente muestra esto, como también aceptan los defensores del concepto hologenómico de evolución (Suárez, 2018, 2020; Lloyd \& Wade 2019). Es necesario probar, además, que los cambios genéticos del microbioma duran el tiempo suficiente como para que esas adaptaciones perduren. Para que esto ocurra, los holobiontes/hologenomas tienen que formar linajes de progenitor-descendiente, es decir, ser reproductores $-\mathrm{o}$, de otro modo, la heredabilidad debe predicarse de los holobiontes/hologenomas como grupo, no de las partes que los componen; ver ecuación (2).

Diferentes autores han elaborado argumentos en contra de la tesis de que el holobionte/hologenoma es un reproductor (Godfrey-Smith, 2015; Moran \& Sloan, 2015;

23 Aunque presentado en tono epistemológico, nótese que el argumento es estrictamente ontológico, pues se trata de determinar dónde, cómo y con qué intensidad tiene lugar la selección natural. 
Douglas \& Werren, 2016; Skillings, 2016; Hurst, 2017), pero tal vez la versión más elaborada de la crítica se encuentra en Stencel \& Wloch-Salamon (2018), por lo que me limitaré a exponer su argumentación.

De acuerdo con Stencel \& Wloch-Salamon el criterio principal para determinar si un colectivo de múltiples especies es un reproductor - al que ellos se refieren como individuo Darwiniano, siguiendo a Godfrey-Smith (2009) - consiste en probar que los diferentes individuos que constituyen el colectivo son incapaces de reproducirse de manera autónoma. Dicho de otro modo: habría que mostrar que el único modo en que cada una de las partes que constituyen el grupo o colectivo se reproduce es por medio de la creación de nuevos grupos o colectivos. En el caso en que la interacción se produce entre organismos de diferentes especies, esto ocurre en ciertas asociaciones binarias entre hospederos y simbiontes, situaciones a las que Queller (2000) se ha referido con el nombre de «transiciones igualitarias» (egalitarian transitions) en individualidad biológica. Ejemplos de tales asociaciones incluyen el origen de la célula eucariota por secuestro de organismos de vida libre que evolucionan en mitocondrias, o el origen de muchos endosimbiontes en ciertos insectos (la asociación entre áfidos y Buchnera aphidicola es tal vez el caso más estudiado). Fuera de estos casos, que podemos considerar excepcionales, este tipo de transiciones no se observan: los microorganismos habitualmente preservan su capacidad de reproducirse y, de hecho, habitualmente se reproducen al margen de su hospedero. ${ }^{24}$ Esto es cierto para prácticamente todos los microorganismos que constituyen el microbioma de un holobionte/hologenoma y, por tanto, es incorrecto afirmar que se trate de un reproductor, según Stencel \& WlochSalamon (2018).

El argumento de Stencel \& Wloch-Salamon (2018) concierne fundamentalmente al momento en el cual puede decirse que la selección natural que opera a un nivel $N_{i}$ apantalla/cancela todo posible efecto de la selección natural $N_{i+l}$, entendidos ambos niveles de manera jerárquica. De otro modo, cuándo es posible decir que la selección actuante a los niveles inferiores no anula los efectos de la selección actuante a niveles superiores. La única manera en que se cree que esto puedo ocurrir entre dos especies diferentes es por el proceso denominado «fidelidad de compañía» (partner fidelity). Es decir, cuando dos linajes concretos se asocian de manera transgeneracionalmente estable, con una conexión estricta entre los genotipos. Es decir, que la reproducción del primero esté siempre condicionada a la reproducción del segundo y viceversa, y que ambos linajes coocurran siempre juntos (Douglas \& Werren, 2016). ${ }^{25}$ Este requisito es algo fundamental, como confirman algunos modelos genéticos (van Vliet \& Doebeli, 2019). La única manera de que esto ocurra es que evolucione algún mecanismo de transmisión vertical de los simbiontes junto con su hospedero - secuestro del linaje- o que se genere algún mecanismo de adquisición horizontal que garantice que ambos linajes coocurran siempre. ${ }^{26}$

24 Técnicamente, esto es más complicado, porque tanto los orgánulos en la célula eucariota como los endosimbiontes en muchos insectos aún conservan los genes que controlan su reproducción. Lo que ocurre es que su reproducción lleva a la muerte si su hospedero no se reproduce también y ellos son transferidos al nuevo hospedero.

25 Es interesante comprobar que este requisito también era exigido por Zilber-Rosenberg \& Rosenberg (2008, p. 726), aunque posteriormente relajan dicho criterio.

26 Estrictamente hablando, no es preciso afirmar que la transmisión vertical y la adquisición horizontal lleven al mismo tipo de reproductor, lo que ha llevado a Lloyd \& Wade (2019) a distinguir entre los 
El argumento de Stencel \& Wloch-Salamon no es incorrecto, especialmente si alguien mantiene que el holobionte/hologenoma es la unidad de selección primaria - como hacen, por ejemplo, Zilber-Rosenberg \& Rosenberg (2008), Dupré \& O’Malley (2009, p. 15), o Gilbert et al. (2012) - . No obstante, su razonamiento enmascara una pequeña confusión, a saber: que el marco correcto para pensar el concepto de reproductor es el de las «transiciones mayores en la evolución» (major transitions in evolution) de Maynard-Smith \& Szathmáry (1995). Pero dicho marco presupone que un nuevo nivel de selección solo puede evolucionar cuando la ecuación (3) es verdadera (aunque cf. Clarke, 2014, 2016), es decir:

(3) $\operatorname{Cov}\left(w_{i}, p_{i}\right)=0 ; \operatorname{Cov}\left(w_{k}, p_{k}\right)=1$

Desde luego, Stencel \& Wloch-Salamon (2018) tienen razón que la selección en el nivel superior será máximamente efectiva cuando (3) se satisface, porque toda la selección a nivel inferior queda apantallada/cancelada. Pero se equivocan al afirmar que esa es la única situación en que la selección al nivel del holobionte/hologenoma es eficiente a nivel adaptativo. Basta que $h \operatorname{Cov}\left(w_{k}, p_{k}\right) \neq 0$, donde $k$ es el grupo o, lo que es lo mismo, que la ecuación (4) sea verdadera. Esto es:

$$
\text { (4) } 1>\operatorname{Cov}\left(w_{i}, p_{i}\right)>0 ; 1>\operatorname{Cov}\left(w_{k}, p_{k}\right)>0
$$

Nótese que esta crítica afecta una de las asunciones fundamentales de los quienes niegan la validez del concepto hologenómico de evolución, a saber: que la transmisión vertical del microbioma es esencial para conceptualizar el holobionte/hologenoma como reproductor. Dicha asunción, de hecho, ha sido asumida incluso por defensores del concepto hologenómico de evolución, tales como Lloyd \& Wade (2019). Estos autores, en consonancia parcial con los críticos, consideran que un holobionte/hologenoma será un reproductor siempre que el grado de transmisión vertical sea no nulo. Es decir, si al menos uno de los microorganismos del microbioma se transmite verticalmente, el holobionte/hologenoma es, para Lloyd \& Wade (2019), un reproductor. La diferencia de Lloyd \& Wade con los críticos del concepto hologenómico de evolución estriba en que a los primeros les basta con que un solo microorganismo se transmita verticalmente para predicar el carácter del holobionte/ hologenoma como reproductor, cosa que los segundos niegan en rotundo. Pero, como he apuntado con mi crítica, y contradiciento tanto a los críticos como a Lloyd \& Wade (2019), la transmisión vertical de los microorganismos no es estrictamente necesaria siempre y cuando haya algún otro mecanismo de adquisición horizontal que garantice que la heredabilidad a nivel del holobionte sea no nula (ver también Veigl et al., 2019; Suárez, 2020). Asimismo, y para apuntalar mi crítica a Lloyd \& Wade (2019), la existencia de transmisión vertical no es ni siquiera estrictamente suficiente en ciertas ocasiones, pues como enfatizan los críticos de la aplicación del concepto de reproductor al holobionte/hologenoma, se necesitan condiciones más estrictas (ver también 4.1.). Lloyd \& Wade (2019), por tanto, fallan en su argumentación a la hora de defender que el holobionte es un reproductor.

Otro sesgo que subyace tanto a la crítica de Stencel \& Wloch-Salamon (2018), como a la réplica de Lloyd \& Wade (2019), es que ambos presuponen que lo que debe heredarse

conceptos de eubolobionte (transmisión vertical/mutualismo y coespeciación), demibionte (adquisición horizontal de organismos de vida libre/mutualismo sin coespeciación) y holobionte (neutral entre ambos conceptos). Ignoraré estas dificultades en este trabajo. 
verticalmente para hablar del holobionte/hologenoma como reproductor son los taxones o especies bacterianas. Es más, en el caso de Stencel \& Wloch-Salamon la crítica es incluso más seria: no es solo que deban transmitirse verticalmente junto con el hospedero, sino que no deben existir en vida libre - $\mathrm{o}$, dicho de otro modo, no debe ser posible que aquellos microorganismos que viven en el hospedero puedan potencialmente residir en otros nichos. Estas dos condiciones, como es obvio, resultan innecesarias si uno adopta la perspectiva funcional (modelo de estabilidad de rasgos) para caracterizar los constituyentes del microbioma en el holobionte/hologenoma que se ha defendido en la sección 3.1 .

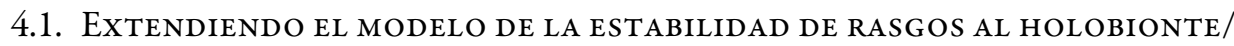 HOLOGENOMA COMO REPRODUCTOR}

En la sección 3.1. argumenté que el modelo de la estabilidad de rasgos suponía: primero, que la base genética de los rasgos del microbioma que incrementaban la eficacia biológica del hospedero incrementaría su frecuencia en la población; segundo, que aquellos hospederos que favorecían fenómenos tales como HGT y redundancia funcional de las bases genéticas de tales rasgos también incrementarían su frecuencia en la población. Ahora bien, no he argumentado aún que esto llevará a ciertos efectos acumulativos a nivel del holobionte/ hologenoma. Por tanto, el modelo de estabilidad de rasgos es tan pobre como el resto de los modelos del holobionte/hologenoma a la hora de dar cuenta de la existencia de adaptaciones hologenómicas. Es necesario pues especificar posibles mecanismos que muestren que existe una cierta afinidad - heredabilidad - a nivel del holobionte/hologenoma que permita hablar de linajes progenitor-descendiente a su nivel específico.

Sin embargo, es importante matizar un punto. En las secciones 2 y 4 dije que la argumentación en favor del rol del holobionte/hologenoma no puede consistir sencillamente en ilustrar posibles mecanismos que garanticen la herencia de microorganismos, ni siquiera cuando estos involucran casos como la transmisión vertical. Ahora estamos en condiciones de ver por qué. Si de lo que se trata al introducir el concepto de reproductor es captar linajes genuinos en que puedan surgir adaptaciones, entonces tenemos que probar que tales mecanismos de herencia son realmente tales, y no meras circunstancias que llevan accidentalmente a la coocurrencia transgeneracional de hospedero y simbiontes (Suárez \& Triviño, 2020). Dicho de otro modo, hay que mostrar que tales mecanismos, o bien son ellos mismos resultado de la selección del holobionte/hologenoma como grupo, o bien dan lugar a adaptaciones a nivel del grupo que no existirían si no hubiese holobionte/hologenoma. Si no probamos de algún modo que esto último es así estaríamos confundiendo lo que Ariew \& Lewontin (2004) denominan reproducción de (reproduction of) con reproducción por (reproduction by) o, dicho de otro modo, casualidad con causalidad. La pregunta, por tanto, es: 1) ¿hay casos que justifiquen la afirmación de que el holobionte/hologenoma es un reproductor? Y, en caso afirmativo: 2) ¿cuáles son las condiciones específicas que permiten apreciar que el holobionte/hologenoma es un reproductor?

La respuesta a 1) es que sí, aunque con matices; a saber: el concepto hologenómico - en la versión de estabilidad de rasgos que se defiende aquí- no pretende defender que la totalidad de rasgos de un hospedero tienen origen hologenómico, ni tampoco que todos los hospederos han sido necesariamente reproductores en su versión de holobiontes/hologenomas. Es obvio tanto que algunos rasgos estarán controlados por los genes transmitido en el genoma del hospedero (por ejemplo, el color de ojos), como que no todas las especies de 
animales tienen por qué portar adaptaciones hologenómicas. La hipótesis del hologenoma explica el origen y mantenimiento de algunos rasgos, en algunos linajes de animales y plantas. Identificar cuáles son esos rasgos y cuáles son los linajes requiere determinar las condiciones biológicas específicas para caracterizar al holobionte como reproductor, y por tanto requiere responder previamente a la segunda pregunta.

A nivel puramente teórico, el holobionte/hologenoma será un reproductor siempre que, siendo $k$ un elemento de una población de holobiontes/hologenomas, $b \operatorname{Cov}\left(w_{k}, p_{k}\right) \neq 0$. Es decir, siempre que la selección natural actuante al nivel focal del holobionte/hologenoma sea no nula, lo cual requiere una covarianza positiva entre los rasgos hologenómicos y la eficacia hologenómica (entendida como capacidad de formar nuevos holobiontes/hologenomas), más un grado de heredabilidad, entendida en sentido amplio (ver sección 2), no nulo. Nótese que el concepto de heredabilidad expresado en este caso no se refiere al mero control de la composición del microbioma por parte del hospedero, sino al grado de similitud global de ciertos rasgos fenotípicos del holobionte/hologenoma a través de las diferentes generaciones de holobiontes/hologenomas (para una discusión, ver van Opstal \& Bordenstein, 2015).

Así expuesta, esta condición no es en cambio biológicamente informativa. Para que lo sea, debe darse el paso de explicar lo que se requiere a nivel biológico (Figura 6). En este último nivel se requieren tres elementos para poder hablar de linajes de holobiontes/hologenomas, de acuerdo con el criterio de estabilidad de rasgos:

(a) La evolución de rasgos en el microbioma cuya base genética tiene su eficacia conectada (fitness aligned) al hospedero y solo al hospedero, a pesar de expresarse fenotípicamente a través de los microbios que portan los genes que codifican el rasgo.

(b) La evolución de rasgos en el hospedero directamente ligados a garantizar la estabilidad transgeneracional de esos rasgos codificados por el microbioma, pero no necesariamente de los taxones que los portan — recordemos que esos rasgos pueden ser compartidos por varios taxones como se explica en la sección $3.1-$.

(c) El establecimiento de epistasis genéticas entre los linajes de hospederos y las bases genéticas de los rasgos codificados por el microbioma que incrementan la eficacia biólogica del hospedero mediante el incremento de la propia eficacia biológica de las bases genéticas de los rasgos del microbioma, pero no la de los linajes de microbios que las portan.

Expliquemos las razones de introducir (a)-(c) de manera más detallada. (a) se introduce para determinar que la base genética del rasgo que evoluciona sea en efecto un rasgo del linaje hologenómico, y no del linaje del microbio. De otro modo, si el rasgo genético que evoluciona en el microbioma fuese selectivamente ventajoso para el microbio en cualquier ambiente, entonces se trata de una adaptación del microbio, no del hologenoma. La base genética de los rasgos del holobionte/hologenoma como reproductor tienen que desaparecer -o evolucionar con una fuerza selectiva $s=0-$ de la población de microrganismos cuando estos no se asocian con la especie (o especies) de hospederos para la que ha evolucionado. (b) se introduce para garantizar que existan afinidades selectivas entre ciertos hospederos y bases genéticas del microbioma, determinadas estas últimas funcionalmente en vez de taxonómicamente (Taxis et al., 2015; Suárez, 2016; Lemanceau et al., 2018). Nótese que las afinidades selectivas entre hospedero y microbioma funcional son solamente exigidas desde la perspectiva del reproductor, pero no desde la perspectiva del interactor, como 
lo demuestra el hecho de que en el modelo presentado en la sección 3 presupone que las asociaciones son azarosas. Por último, la introducción de (c) hace referencia a el modo en que tiene lugar la coevolución en los holobiontes/hologenomas, tal como expliqué anteriormente (ver Figura 5).

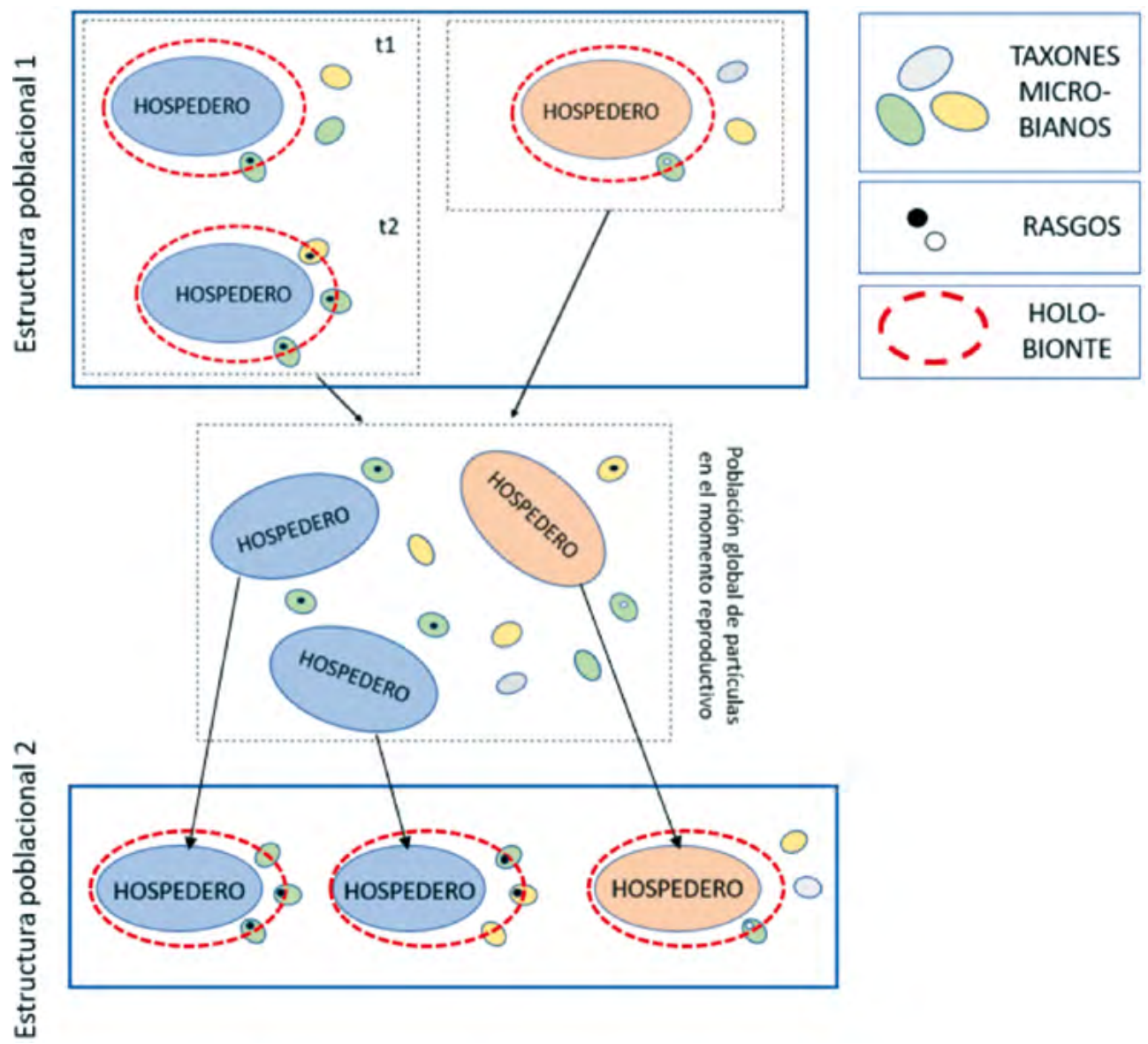

Figura 6

Ejemplificación del holobionte/hologenoma como reproductor de acuerdo con el modelo de estabilidad de rasgos. Lo que se requiere es que los rasgos que evolucionan en los microorganismos generen afinidades con ciertos tipos de hospederos, de una forma tal que se puedan reconocer linajes. En la figura, los rasgos representados en negro generan afinidad con los hospederos gris claro, y los blancos con los hospederos gris oscuro. Esto hace que, transgeneracionalmente, la estructura poblacional sea tal que las afinidades generen una divergencia cada vez mayor entre hospederos gris claro y hospederos gris oscuro. Nótese que esto no se debe a la transmisión vertical de microorganismos con los rasgos negros y/o blancos, pues se presupone que los hospederos seleccionan sus microorganismos de una población global de partículas. La adquisición es por tanto horizontal, pero con afinidad selectiva. 
Se dirá, por tanto, que un holobionte/hologenoma es un reproductor según el modelo de la estabilidad de rasgos cuando hay al menos algún mecanismo biológico que posibilita la satisfacción de (a)-(c). Revisar tales mecanismos estaría fuera del alcance de este trabajo, toda vez que son además múltiplemente realizables en diferentes taxones biológicos, pero baste mencionar casos como los rasgos específicos que han evolucionado para posibilitar la dieta hematófaga en murciélagos vampiros (Mendoza et al., 2018; Suárez, 2020); los rasgos que han evolucionado para posibilitar la dieta herbívora en ciertos rumiantes (Gilbert, 2019; Chiu \& Gilbert, 2019); la evolución de mecanismos específicos de reconocimiento en los hospederos, incluyendo mecanismos de reconocimiento inmunológico (Chiu \& Eberl, 2016; Greslehner, en prensa); etc.

Veamos cómo (a)-(c) se satisfacen en el caso de la evolución de la hematofagia en murciélagos vampiros. Para ello, seguiré la argumentación elaborada en Suárez (2020) y Suárez \& Triviño (2020), basada fundamentalmente en el trabajo de Mendoza et al. (2018). La pregunta estructural que los autores se plantean es la siguiente: ¿cómo es posible que solo tres taxones de murciélagos, de entre todos los taxones de murciélagos y de entre todos los taxones de mamíferos, hayan evolucionado para tener una dieta estrictamente hematófaga? La importancia de la pregunta se sustenta en dos observaciones: (1) que una dieta estrictamente hematófaga plantea serios retos a nivel fenotípico; es decir, una dieta hematófaga requiere de adaptaciones muy sofisticadas a nivel renal, hepático, inmunológico, o morfológico que son bastante exclusivos de esta forma de vida; (2) que el genoma de los murciélagos vampiros es funcionalmente muy pobre; es decir, no contiene los grupos funcionales que le permiten solucionar los retos fenotípicos planteados por la propia dieta. El problema fundamental, por tanto, es que (1) y (2) no encajan entre sí, pues es por un lado claro que los murciélagos poseen las adaptaciones que permiten la hematofagia, y es por otro lado claro que no las poseen «intrínsicamente», es decir, en su genoma. Ante tamaño problema, Mendoza et al. (2018) teorizan la posibilidad de que parte de dichas adaptaciones estén codificadas en el microbioma, hipótesis que arroja resultados positivos en vista de un análisis funcional del microbioma de los murciélagos. Esto les lleva a concluir que los murciélagos hematófagos son una unidad de selección en tanto que holobiontes/hologenomas.

Ahora bien, ¿qué es exactamente lo que observan, y cómo deben encajarse las observaciones entre sí para dar solidez a la hipótesis de que el murciélago hematófago en tanto que holobionte/hologenoma es una unidad de selección como reproductor? El análisis de Suárez (2020) y Suárez \& Triviño (2020) encaja tales piezas. Por un lado, Mendoza et al. (2018) han observado que la composición taxonómica del microbioma de los murciélagos hematófagos no es sustancialmente diferente de la composición taxonómica de otros murciélagos no hematófagos (insectívoros, carnívoros, etc.). O, dicho de otro modo, los mismos taxones o especies bacterianas que componen el microbioma de los murciélagos hematófagos componen el microbioma de los murciélagos no hematófagos. En cambio, la divergencia funcional es sustantiva. Lo que Suárez (2020) argumenta en vista de esto, y basándose en la distinción entre el concepto de especie bacteriana usado en filogenética y el análisis bacteriano en términos funcionales que se usa en los estudios simbióticos (Suárez, 2016), es que la afinidad en términos de eficacia biológica se produce entre la base genética que codifica los grupos funcionales de los rasgos del microbioma ligados a esquivar los retos fenotípicos de la dieta hematófaga, y el propio hospedero — es decir, la hipótesis (a) expresada al comienzo de esta sección-. 
En segundo lugar, Mendoza et al. (2018) observan que existe una presión selectiva para ciertos grupos funcionales dentro del microbioma de los murciélagos hematófagos, pero no dentro del microbioma de los murciélagos no hematófagos. Dicha presión selectiva no afecta, en cambio, a los taxones o especies bacterianas que portan la base genética de los rasgos, sino únicamente a tales bases genéticas. Esto lleva a Suárez (2020) a argumentar la existencia de una afinidad epistática entre rasgos del hospedero y grupos funcionales del microbioma que, precisamente, y como teorizaban Lloyd \& Wade (ver sección 3), lleva a una retroalimentación del proceso evolutivo - es decir, la hipótesis (c) introducida al comienzo de esta sección-.

Finalmente, el análisis inmunológico de los murciélagos vampiros muestra afinidades selectivas por microorganismos con ciertos grupos funcionales, las cuales se manifiestan en diferentes momentos del proceso de desarrollo (Suárez 2020). Es decir, la adquisición del microbioma no es vertical, sino horizontal. Ahora bien, tampoco es «gratuita», o, en términos técnicos, mero resultado de un proceso de filtración ecológica (ver nota 26), sino que se trata de un proceso selectivo para el que han evolucionado adaptaciones concretas a nivel del genoma de los murciélagos hematófagos —esto es, la hipótesis (b) introducida al inicio de esta sección-.

De este análisis cabe concluir que estos elementos son suficientes para justificar tanto que algunos holobiontes/hologenomas son reproductores, así como que ciertas adaptaciones han evolucionado a su nivel específico, y no a nivel del hospedero o de los microbios que portan dichos genes (ver Suárez \& Triviño, 2020 para más ejemplos). Queda abierto a investigación empírica determinar cuáles satisfacen estas condiciones, hasta qué punto lo hacen, cuáles pueden ser los diferentes mecanismos específicos que han evolucionado para ello, etc. Pero nada de esto es nuevo en biología - en contra de lo que algunos críticos del papel del holobionte/hologenoma como unidad de selección argumentan- en que prácticamente toda la investigación es altamente específica para cada linaje biológico, el cual habrá seguido sus propios patrones o pautas evolutivos.

Por último, es importante señalar que la heredabilidad en los holobiontes/hologenomas no será nunca tan perfecta como la que ocurre en organismos que se dividen por mecanismos de replicación o división binaria (e.g. microrganismos), ni tampoco como la de aquellos que lo hacen por mecanismos de herencia mendeliana. Al contrario, como argumenta Díaz (2015), en el caso de asociaciones simbióticas será siempre necesario estudiar los dos niveles de selección, pues ambos actúan simultáneamente. O, para decirlo de otro modo, no cabe entender la evolución de los holobiontes/hologenomas desde la perspectiva de las transiciones mayores en la evolución, tal como ya he argumentado en la sección 4. Por tanto, la combinación de MLS1 y MLS2 - es decir, de la perspectiva del interactor y la del reproductor- será siempre necesaria para entender estas dinámicas evolutivas.

\section{Conclusión}

En este trabajo he argumentado que la evidencia empírica actual en favor de la consideración del holobionte/hologenoma como unidad de selección es sólida y, de manera restringida, sirve para apoyar tanto la tesis de que el holobionte/hologenoma es un interactor como un reproductor. En el proceso de elaborar mi posición, he analizado diferentes argu- 
mentos que se habían desarrollado para rechazar que el holobionte/hologenoma fuera un interactor, así como un reproductor, y he mostrado qué aspectos de los argumentos favorables a la tesis de que el holobionte/hologenoma es un nivel de selección en ambos sentidos son válidos y cuáles no. Al final, he defendido que el modelo que define al microbioma en términos funcionales y no taxonómicos, denominado modelo de estabilidad de rasgos, constituye la elaboración más sólida del papel del holobionte/hologenoma como interactor. Asimismo, he extendido el modelo al concepto de reproductor, argumentando que el modelo de estabilidad de rasgos da cuenta del establecimiento de linajes de progenitor-descendiente a nivel del holobionte/hologenoma. En conclusión, el modelo de estabilidad de rasgos se ha defendido como la mejor manera de capturar el modo en que actúa la selección natural a nivel del holobionte/hologenoma y, por tanto, de captar sus posibles efectos evolutivos. Queda por ver cómo aplicar dicho modelo a sistemas biológicos concretos para así poder evaluar su grado de adecuación empírica, así como el grado de eficacia de la selección natural a niveles inferiores como disruptiva de la evolución hologenómica.

\section{Agradecimientos}

El autor agradece a Giorgio Airoldi, David Alvargonzález, Santiago Ginnobili y Guillermo Ponz por su lectura detallada del trabajo, y sus comentarios. Asimismo, gracias a Adrian Stencel, Mark Canciani, John Dupré y Lisa Lloyd por haber leído una primera versión traducida del trabajo y haber dado comentarios extensos a ciertas partes del mismo. Se agradece también la labor de dos revisores anónimos de Theoria, así como de los editores. El trabajo ha sido financiado por el Narodowe Centrum Nauki, OPUS Grant No. 2019/35/B/ HS1/01998.

\section{REFERENCIAS}

Ariew A., \& Lewontin, R. C. (2004). The confusions of fitness. Br J Philos Sci 55, 347-363.

Baedke, J., Fábregas-Tejeda, A., Delgado, A. N. (2020). The hologenome concept before Margulis. JExpZool (MolDevEvol) 334, 149-155.

de Bary A. (1879). Die Erscheinung der Symbiose. Verlag von Karl J. Trübner.

Bennett G.M., \& Moran, N.A. (2015). Heritable symbiosis: the advantages and perils of an evolutionary rabbit hole. PNAS USA 112, 10169-10176.

Booth, A. (2014). Symbiosis, selection and individuality. Bio Philos 29, 657-673.

Bordenstein, S. R., \& Theis, K. R. (2015). Host biology in light of the microbiome: ten principles of holobionts and hologenomes. PLoSBiol 13(8). https://doi.org/10.1371/journal.pbio.1002226.

Bosch, T. C. G., \& Miller, D. J. (2016). The Holobiont Imperative. Dordrecht: Springer.

Bourrat, P. (2019). Evolutionary Transitions in Heritability and Individuality. Theory in Biosciences 138 (2), 305-23.

Bourrat, P., \& Griffiths, P. (2018). Multispecies individuals. History and Philosophy of the Life Sciences 40(2), 33. https://doi.org/10.1007/s40656-018-0194-1.

Brandon, R. (1988). Levels of selection: A hierarchy of interactors. In HC Plotkin (ed.). The Role of Behaviour in Evolution: (pp. 51-71). Cambridge, MA: The MIT Press.

Bright, M., \& Bulgheresi, S. (2010). A complex journey: transmission of microbial symbionts. Nat Rev Microbiol 8, 218-230. 
Brooks, A. W., Kohl, K. D., et al. (2016). Phylosymbiosis: relationships and functional effects of microbial communities across host evolutionary history. PLoSBiol 14 (11). https://doi.org/10.1371/journal. pbio. 2000225.

Brucker, R. \& Bordenstein, S. R. (2012). Speciation by Symbiosis. TrendsEcolEvol 27 (8), 443-451.

Brucker, R. \& Bordenstein, S. R. (2013a.) The hologenomic basis of speciation: Gut bacteria cause hybrid lethality in the genus Nasonia. Science 341, 667-669.

Brucker, R. \& Bordenstein, S. R. (2013b). The capacious hologenome. Zoology 116 (5), 260-261.

Buss, L.W. (1987). The Evolution of Individuality. Princeton, NJ: Princeton University Press.

Calcott, B. \& Sterelny, K. (2011). Major transitions in evolution revisited. Cambridge, MA: The MIT Press.

Cerqueda-García, D., \& Falcón, L. I. (2016). La construcción del nicho y el concepto de holobionte, hacia la reestructuración de un paradigma. RevMexBiodiv 87, 1. http://dx.doi.org/10.1016/j.rmb.2015.11.001.

Chandler, J., \& Turelli, M. (2014). Comment on «The hologenomic basis of speciation: gut bacteria cause hybrid lethality in the genus Nasonia». Science 345(6200), 1011.

Chiu, L., \& Eberl, G. (2016). Microorganisms as scaffolds of host individuality: an eco-immunity account of the holobiont. Biol Philos 31(6), 819-837.

Chiu, L., \& Gilbert, S. F. (2019). Niche construction and the transition to herbivory: phenotype switching and the organization of new nutritional modes. In H. Levine, M. K. Jolly, P. Kulkarni, and V. Nanjundiah (eds.). Phenotypic Switching: Implications in Biology and Medicine: (pp. 459-483). Cambridge, MA: Academic Press.

Clarke, E. (2013). The multiple realizability of biological individuals. The Journal of Philosophy CX(8), 413435 .

Clarke, E. (2014). Origins of evolutionary transitions. JBiosci 39(2), 307-317.

Clarke, E. (2016). Levels of selection in biofilms: multispecies biofilms are not evolutionary individuals. Biol Philos 31, 191-212.

Dawkins, R. (1976). The Selfish Gene. New York: Oxford University Press [ed. cast. El gen egoista. Barcelona: Salvat 2000].

Damuth, J., \& Heisler, I. L. (1988). Alternative formulations of multilevel selection. Biol Philos 3, 407-430.

Díaz, J.S. (2015). El mecanismo evolutivo de Margulis y los niveles de selección. Contrastes. Revista internacional de filosofia XX(1), 7-26.

Diéguez, A. (2012). La vida bajo escrutinio. Madrid: Biblioteca Buridán.

Doolittle, W.F., \& Booth, A. (2017). It's the song not the singer: an exploration of holobiosis and evolutionary theory. Biol Philos 32(1), 5-24.

Douglas, A.E. (2010). The symbiotic habit. Princeton, NJ: Princeton University Press.

Douglas, A.E., \& Werren, J.H. (2016). Holes in the hologenome: why host-microbe symbioses are not holobionts. $m$ Bio 7 (2). https://doi.org/10.1128/mBio.02099-15.

Drown D.M., \& Wade, M.J. (2014). Runaway coevolution: adaptation to heritable and nonheritable environments. Evolution 68(10), 3039-3046.

Drown D.M., Zee, P.C., et al. (2013). Evolution of transmission mode in obligate symbionts. EvolEcolRes 15, 43-59.

Dupré, J. (2012). Processes of life: Essays in the Philosophy of Biology. Oxford: Oxford University Press.

Dupré, J., \& O'Malley, M.A. (2009). Varieties of living things: Life at the intersection of lineage and metabolism. Philosophy \& Theory in Biology 1: e003. http://dx.doi.org/10.3998/ptb.6959004.0001.003

Frank, S.A. (2011). Natural selection. II. Developmental variability and evolutionary rate. Journal of Evolutionary Biology 24, 2310-2320.

Gilbert, S.F. (2014). A holobiont birth narrative: The epigenetic transmission of the human microbiome. Frontiers in Genetics 5, 282. https://doi.org/10.3389/fgene.2014.00282

Gilbert, S.F. (2019). Developmental symbiosis facilitates the multiple origins of herbivory. Evolution \& Development 22, 154-164.

Gilbert, S.F., \& Chiu, L. (2015). The birth of the holobiont. Multispecies birthing through mutual scaffolding and niche construction. Biosemiotics 8, 191-210. 
Gilbert, S.F., \& Tauber, A.I. (2016). Rethinking Individuality: The Dialectics of the Holobiont. Biol Philos 31(6), 839-853.

Gilbert, S.F., Sapp, J., \& Tauber, A.I. (2012). A symbiotic view of life: We have never been individuals. The Quarterly Review of Biology 87(4), 325-341.

Gilbert, S.F., Rosenberg, E. \& Zilber-Rosenberg, I. (2017). The holobiont with its hologenome is a level of selection in evolution. In S. B. Gissis, E. Lamm, and A. Shavit (eds.). Landscapes of collectivity in the life sciences: (pp. 305-324). London: The MIT Press.

Gildenhuys, P. (2019). Natural selection. In E.N. Zalta (ed.) The Stanford Encyclopaedia of Philosophy. https://plato.stanford.edu/cgi-bin/encyclopedia/archinfo.cgi?entry=natural-selection.

Ginnobili, S. (2010). La teoría de la selección natural darwiniana. Theoria 25(1), 37-58.

Ginnobili, S. (2018). La teoría de la selección natural - Una exploración metacientifica. Bernal: Universidad Nacional de Quilmes.

Godfrey-Smith, P. (2009). Darwinian populations and natural selection. Oxford: Oxford University Press.

Godfrey-Smith, P. (2013). Darwinian Individuals. In F Bouchard \& P Huneman (eds.): From group to individuals: evolution and emerging individuality. Cambridge, MA: The MIT Press.

Godfrey-Smith, P. (2015). Reproduction, symbiosis, and the eukaryotic cell. PNAS 112(33), 10120-10125.

Goodnight, C.J. (2005). Multilevel selection: the evolution of cooperation in non-kin groups. Popul Ecol 47, 3-12.

Goodnight, C.J. (2015). Multilevel selection theory and evidence: a critique of Gardner. Journal of Evolutionary Biology 28, 1734-1746.

Greslehner, G. (En prensa). Can the immune system recognize biological functions? Studies in the History and Philosophy of the Life Sciences Part $C$.

Griesemer, J. (2000). The units of evolutionary transition. Selection 1(3), 67-80.

Griffiths, P.E., \& Gray, R.D. (1994). Developmental systems and evolutionary explanation. The Journal of Philosophy 91(6), 277-304.

Griffiths, P.E., \& Gray, R.D. (1997). Replicator II-judgement day. Biol Philos 12(4), 471-492.

Griffiths, P.E., \& Hochman, A. (2015). Developmental systems theory. In H. Kehrer-Sawatzi (ed.). eLS (pp. 1-7). Chichester, UK: John Wiley \& Sons.

Guerrero, R., Margulis, L. \& Berlanga, M. (2013). Symbiogenesis: The holobiont as a unit of evolution. International Microbiology 16(3), 133-143.

Henry, L.P., \& Ayroles, J.F. (2020). The microbiome responds to Evolve and Resequence experiments in Drosophila melanogaster. bioRxiv. https://doi.org/10.1101/2020.03.19.999078

Hull, D.L. (1980). Individuality and Selection. Annual Review of Ecology and Systematics 11, 311-332.

Hull, D.L. (1988). Science as a process. Chicago: University of Chicago Press.

Hurst, G.D.D. (2017). Extended genomes: symbiosis and evolution. Interface Focus 7 (5). https://doi. org/10.1098/rsfs.2017.0001

Kramer, J., \& Meunier, J. (2016). Kin and multilevel selection in social evolution: a never ending controversy? F1000Research 5, 776. https://doi.org/10.12688/f1000research.8018.1

Lavagnino, N.J., Massarini, A. \& Folguera, G. (2014). Simbiosis y evolución: Un análisis de las implicaciones evolutivas de la obra de Lynn Margulis. Revista Colombiana de Filosofía de la Ciencia 14 (29), 161-181.

Lemanceau, P., Blouin, M., et al. (2017). Let the core microbiota be functional. TRENDS in Plant Science 22(7), 583-595.

Lewontin, R.C. (1970). The units of selection. AnnuRevEcolEvolSyst 1, 1-18.

Lewontin, R.C. (1985). Adaptation. In R. Levins \& R.C. Lewontin (eds.): The Dialectical Biologist: (pp. 6584). Cambridge, MA: Harvard University Press.

Lloyd, E. (1994). The Structure and Confirmation of Evolutionary Theory. Princeton, NJ: Princeton University Press.

Lloyd, E. (2015). Adaptationism and the Logic of Research Questions: How to Think Clearly About Evolutionary Causes. BiolTheor 10, 343-362. 
Lloyd, E. (2017a). Units and Levels of selection. In E. N. Zalta (ed.) Stanford Encyclopaedia of Philosophy. https://plato.stanford.edu/entries/selection-units/

Lloyd, E. (2017b). Holobionts as units of selection: Holobionts as interactors, reproducers, and manifestors of adaptation. In S. B. Gissis, E. Lamm, \& A. Shavit (Eds.). Landscapes of Collectivity in the Life Sciences (pp. 351-368). Cambridge, MA: The MIT Press.

Lloyd, E. (En prensa). Adaptation. Cambridge: Cambridge University Press.

Lloyd, E., \& M.J. Wade. (2019) Criteria for holobionts from community genetics. Biol Theor. 14, 151-170.

Louca, S., Jacques, S.M.S., et al. (2016). High taxonomic variability despite stable functional structure across microbial communities. NatEcolEvol 1, 15. https://doi.org/10.1038/s41559-016-0015.

Luque, V. (2017). One equation to rule them all: A philosophical analysis of the Price equation. Biol Philos $32,97-125$.

Luque, V. (2018). George Price y el lenguaje de la evolución. eVOLUCIÓN 13(1), 33-42.

Lynch, J.B., \& Hsiao, E.Y. (2019). Microbiomes as sources of emergent host phenotypes. Science 365(6460), 1405-1409.

Marchesi, J.R., \& Ravel, J. (2015). The vocabulary of microbiome research: A proposal. Microbiome 3(31). https://doi.org/10.1186/s40168-015-0094-5.

Margulis, L. (1990). Words as battle cries: Symbiogenesis and the new field of endocytobiology. Bioscience 40(9), 673-677.

Margulis, L. (1991). Symbiogenesis and symbioticism. In L. Margulis, and R. Fester (eds.). Symbiosis as a source of evolutionary innovation: (pp. 1-14). London. The MIT Press.

Maynard-Smith, J. (1988). Evolutionary progress and levels of selection. In Nitecki M.H. (eds). Evolutionary Progress: (pp. 219-230). Chicago: University of Chicago Press.

Maynard-Smith, J. (1991). A Darwinian view of symbiosis. In Margulis, L., and Fester, R. (eds.). Symbiosis as a source of evolutionary innovation (pp. 26-39). Cambridge, MA: The MIT Press.

Maynard-Smith, J., \& Szathmary, E. (1995). The Major Transitions in Evolution. Oxford: Oxford University Press.

McFall-Ngai, M. (2015). Giving microbes their due - animal life in a microbially dominant world. J Exp Biol 218, 1968-1973.

McFall-Ngai, M., M.G. Hadfield, et al. (2013). Animals in the bacterial world, a new imperative for the life sciences. PNAS USA 110(9), 3229-3236.

Mendoza, M.L.Z., Z. Xiong, M. Escalera-Zamudio, et al. (2018). Hologenomic adaptations underlying the evolution of sanguivory in the common vampire bat. Nature Ecol Evol 2, 659-668.

Moran, N.A. (2006). Symbiosis. Current Biology 16(20), R866-R871. https://doi.org/10.1016/j. cub.2006.09.019.

Moran, N.A., \& Sloan, D.B. (2015). The Hologenome Concept: Helpful or Hollow? PLoSBiol 13(12). https://doi.org/10.1371/journal.pbio.1002311.

Moreno, A., \& Mossio, M. (2015). Biological Autonomy. A Philosophical and Theoretical Enquiry. Berlin: Springer.

Okasha, S. (2006). Evolution and the levels of selection. Oxford: Oxford University Press.

Okasha, S. (2014). The relation between kin and multilevel selection theory: An approach using causal graphs. BrJPhilScien 67(2), 435-470.

van Opstal, E.J., \& Bordenstein, S.R. (2015). Rethinking heritability of the microbiome. Science 349, $1172-$ 1173.

Osmanovic D., D.A. Kessler, Y. Rabin, \& Y. Soen. (2018). Darwinian selection of host and bacteria supports emergence of Lamarckian-like adaptation of the system as a whole. BiolDirect 13(1), 24. https://doi. org/10.1186/s13062-018-0224-7.

Pradeu, T. (2010). What is an organism? An immunological answer. History and Philosophy of the Life Sciences 32(3), 247-267.

Pradeu, T. (2016). Organisms or biological individuals? Combining physiological and evolutionary individuality. Biol Philos 31, 797-817. 
Pradeu, T. (2020). Philosophy of immunology. Cambridge: Cambridge University Press.

Price, G.R. (1970). Selection and covariance. Nature 227, 520-521.

Price, G.R. (1972). Extension of covariance selection mathematics. AnnHum Genet 35, 485-490.

Queller, D.C. (2000). Relatedness and the Fraternal Major Transitions. Philosophical Transactions: Biological Sciences 355(1403), 1647-1655.

Queller, D.C., \& Strassmann, J.E. (2016). Problems of multispecies organisms: endosymbionts to holobionts. Biol Philos 31, 855-873.

Rohwer, F., Seguritan, V., et al. (2002). Diversity and distribution of coral-associated bacteria. Mar Ecol Prog Ser 243, 1-10.

Rosenberg, E., \& Zilber-Rosenberg, I. (2013). The Hologenome Concept. London: Springer.

Rosenberg, E., \& Zilber-Rosenberg, I. (2018). The hologenome concept of evolution after 10 years. Microbiome 6(1), 78. https://doi.org/10.1186/s40168-018-0457-9.

Roughgarden, J., Gilbert, S.F., et al. (2018). Holobionts as units of selection and a model of their population dynamics and evolution. BiolTheor 13(1), 44-65.

Roughgarden, J. (2020). Holobiont Evolution: Mathematical Model with Vertical vs. Horizontal Microbiome Transmission. Philosophy, Theory and Practice in Biology 12, 2.

Rudman, S. M., Greenblum, S., et al. (2019). Microbiome composition shapes rapid genomic adaptation of Drosophila melanogaster. PNAS USA 116, 20025-20032.

Skillings, D. (2016). Holobionts and the ecology of organisms: Multi-species communities or integrated individuals? Biol Philos 31, 875-892.

Sober, E. (1993). Philosophy of biology. New York: Westview Press [ed. cast. Filosofía de la biologia. Madrid: Alianza. 1996.]

Sober, E., \& Wilson, D.S. (1998). Unto Others: The Evolution and Psychology of Unselfish Behavior. Cambridge MA: Harvard University Press.

Stencel, A. (2016). The relativity of Darwinian populations and the ecology of endosymbiosis. Biol Philos 31(5), 619-637.

Stencel, A., \& Proszewska, A. (2017). How research on microbiomes is changing biology: A discussion of the concept of the organism. Foundations of Science 23(4), 603-620.

Stencel, A., \& Wloch-Salamon, D.M. (2018). Some theoretical insights into the hologenome theory of evolution and the role of microbes in speciation. Theory Biosci. 137(2), 197-206.

Sterner, B. (2015). Pathways to Pluralism about Biological Individuality. Biol Philos 30 (5), 609-628.

Suárez, J. (2016). Bacterial species pluralism in the light of medicine and endosymbiosis. Theoria 31(1), 91-105.

Suárez, J. (2018). The importance of symbiosis in philosophy of biology: An analysis of the current debate on biological individuality and its historical roots. Symbiosis 76(2), 77-96.

Suárez, J. (2020). The stability of traits conception of the hologenome: An evolutionary account of holobiont individuality. History and Philosophy of the Life Sciences 42,11. https://doi.org/10.1007/s40656020-00305-2.

Suárez, J., \& Stencel, A. (2020). A part-dependent account of biological individuality: Why holobionts are individuals and ecosystems simultaneously? Biological Reviews. Online first. https://doi.org/10.1111/ brv. 12610 .

Suárez, J., \& Triviño, V. (2019). A metaphysical approach to holobiont individuality: Holobionts as emergent individuals. Quaderns de Filosofia 6(1), 59-76.

Suárez, J., \& Triviño, V. (2020). What is a hologenomic adaptation? Emergent individuality and inter-identity in multispecies systems. Frontiers in Psychology 11, 187. doi: https://doi.org/10.3389/ fpsyg.2020.00187.

Taxis T.M., Wolff, S., et al. (2015). The players may change but the game remains: network analyses of ruminal microbiomes suggest taxonomic differences mask functional similarity. Nucleic Acids Research 43(20), 9600-9612.

Theis K.R., Dheilly, N.M., et al. (2016). Getting the hologenome concept right: an ecoevolutionary framework for hosts and their microbiomes. mSystems 1(2). https://doi.org/10.1128/mSystems.00028-16. 
Veigl, S., Suárez, J. \& Stencel, A. (2019). Does inheritance need a rethink? Conceptual tools to extend inheritance beyond DNA. Extended Evolutionary Synthesis. https://extendedevolutionarysynthesis.com/ inheritance-rethink/.

van Vilet, S., \& Doebeli, M. (2019). The role of multilevel selection in host microbiome evolution. PNAS USA 116(41), 20591-20597.

Vrba, E. \& Gould, S. J. 1986. The hierarchical expansion of sorting and selection: Sorting and selection cannot be equated. Paleobiology 12 (2), 217-228.

Wade, M. J. (2016). Adaptation in Metapopulations: How Interaction Changes Evolution. Chicago, IL: University of Chicago Press.

Werren, J.H., Baldo, L., Clark, M.E. (2008). Wolbachia: master manipulator of invertebrate biology. Nature Reviews Microbiology 6, 741-51.

Zilber-Rosenberg, I. and Rosenberg, E. (2008). Role of microorganisms in the evolution of animals and plants: the hologenome theory of evolution. FEMS Microbiol Ecol 32 (5), 723-735.

JaVIER SUÁREz es actualmente investigador principal del proyecto «MULTISPECIES - Network modelling of multispecies systems. Ontological and epistemological implications», financiado por el Centro Nacional de Investigaciones Científicas de Polonia (Narodowe Centrum Nauki) en la Universidad Jagelónica de Cracovia. Investiga en la intersección entre la biología y la filosofía de la ciencia, con especial énfasis en el estudio de la ontología de evolución biológica, el concepto hologenómico de evolución y la naturaleza de la explicación en las ciencias de la vida. Ha publicado trabajos en Biological Reviews, Studies in the History and Philosophy of Science, Symbiosis y Synthese, entre otros. Sus trabajos pueden consultarse en https://philpeople.org/profiles/javier-suarez-2

Address: Department of Philosophy of the Natural Sciences, Institute of Philosophy, Jagiellonian University. Grodka 52, Room 42, 33-332, Krakow (Poland). Email: javier.suarez@uj.edu.pl

ORCID-id: 0000-0001-5851-2277 